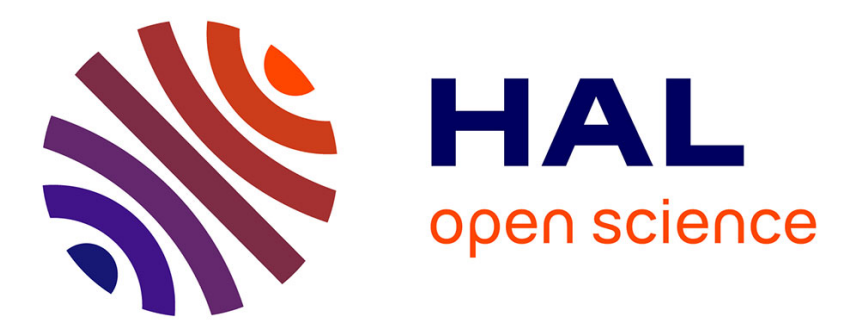

\title{
Dynamic contrast-enhanced MRI: Study of inter-software accuracy and reproducibility using simulated and clinical data
}

Luc Beuzit, Pierre-Antoine Eliat, Vanessa Brun, Jean-Christophe Ferré, Yves Gandon, Elise Bannier, Hervé Saint-Jalmes

\section{To cite this version:}

Luc Beuzit, Pierre-Antoine Eliat, Vanessa Brun, Jean-Christophe Ferré, Yves Gandon, et al.. Dynamic contrast-enhanced MRI: Study of inter-software accuracy and reproducibility using simulated and clinical data. Journal of Magnetic Resonance Imaging, 2016, 43 (6), pp.1288-300. 10.1002/jmri.25101 . hal-01255866

\section{HAL Id: hal-01255866 \\ https://hal-univ-rennes1.archives-ouvertes.fr/hal-01255866}

Submitted on 13 Jun 2016

HAL is a multi-disciplinary open access archive for the deposit and dissemination of scientific research documents, whether they are published or not. The documents may come from teaching and research institutions in France or abroad, or from public or private research centers.
L'archive ouverte pluridisciplinaire HAL, est destinée au dépôt et à la diffusion de documents scientifiques de niveau recherche, publiés ou non, émanant des établissements d'enseignement et de recherche français ou étrangers, des laboratoires publics ou privés. 
Dynamic contrast-enhanced MR imaging: study of inter-software accuracy and reproducibility using simulated and clinical data

\section{Detailed author list}

Luc Beuzit ${ }^{1}$, MD

Pierre-Antoine Eliat ${ }^{2}, \mathrm{PhD}$

Vanessa Brun ${ }^{1}$, MD

Jean-Christophe Ferré ${ }^{1,3}, \mathrm{MD}, \mathrm{PhD}$

Yves Gandon ${ }^{1}$, MD

Elise Bannier ${ }^{1,3}, \mathrm{PhD}$

Hervé Saint-Jalmes ${ }^{4,5}, \mathrm{PhD}$

${ }^{1}$ Department of Radiology, CHU Rennes, 2 Rue Henri Le Guilloux, 35000 Rennes, France

${ }^{2}$ PRISM-Biosit CNRS UMS 3480, INSERM UMS 018, University of Rennes 1, France

${ }^{3}$ Neurinfo MR imaging platform, University of Rennes 1, France

${ }^{4}$ LTSI, UMR 1099, INSERM, University of Rennes 1, France

${ }^{5}$ Eugène Marquis Cancer Institute, Rennes, France

\section{Name and address for correspondence}

Luc Beuzit

Service de radiologie, CHU Pontchaillou

2 Rue Henri Le Guilloux, 35000 Rennes, France

Luc.beuzit@chu-rennes.fr

Tel: (+33)626584881/ (+33) 299284261

\section{Disclosure of funding}

Luc Beuzit received a grant from Rennes University of Medicine for this work ("Prix jeune chercheur")

\section{Short title}

Inter-software variability of DCE-MRI 


\section{Acknowledgements}

MRI data were partly acquired on the Neurinfo MRI research facility from the University of Rennes I. Neurinfo is supported by the the European Union (FEDER), the French State, the Brittany Council, Rennes Metropole, Inria, Inserm and the University Hospital of Rennes.

Giulio Gambarotta (PhD, UMR 1099, INSERM, LTSI, University of Rennes 1, France) participated to the conception of the study.

MRI technicians from Rennes University Hospital participated in MR acquisition. Tracey Westcott (id2m, Rennes) received payment from the authors for her English-language editing assistance. 


\section{Dynamic contrast-enhanced MR imaging: study of inter-software}

\section{accuracy and reproducibility using simulated and clinical data}

\section{Abstract}

Purpose. To test the reproducibility and accuracy of pharmacokinetic parameter measurements on five analysis software packages (SPs) for dynamic contrast-enhanced magnetic resonance (DCE-MR) imaging, using simulated and clinical data.

Materials and Methods. This retrospective study was institutional review board approved. Simulated tissues consisted of pixel clusters of calculated dynamic signal changes for combinations of Tofts model pharmacokinetic parameters (volume transfer constant $\left[K^{\text {trans }}\right]$, extravascular extracellular volume fraction $\left.\left[v_{e}\right]\right)$, longitudinal relaxation time $\left(\mathrm{T}_{1}\right)$. The clinical group comprised 27 patients treated for rectal cancer, with 36 3T DCE-MR scans performed between November 2012 and February 2014, including dual-flip-angle $\mathrm{T}_{1}$ mapping and a dynamic post-contrast $\mathrm{T}_{1}$-weighted, three-dimensional spoiled gradient-echo sequence. The clinical and simulated images were postprocessed with five SPs to measure $K^{\text {trans }}, v_{e}$ and the initial area under the gadolinium curve (iAUGC). Modified Bland-Altman analysis was conducted, intraclass correlation coefficients and within-subject coefficients of variation were calculated.

Results. Thirty one examinations from 23 patients were of sufficient technical quality and post-processed. Measurement errors were observed on the simulated data for all the pharmacokinetic parameters and SPs, with a bias ranging from $-0.19 \mathrm{~min}^{-1}$ to $0.09 \mathrm{~min}^{-1}$ for $K^{\text {trans }},-0.15$ to 0.01 for $v_{e}$, and -0.65 to $1.66 \mathrm{mmol} . \mathrm{L}^{-1} . \mathrm{min}$ for iAUGC. The intraclass correlation coefficient between SPs revealed moderate agreement for the simulated data 
$\left(K^{\text {trans }}: 0.50 ; v_{e}: 0.67\right.$; iAUGC: 0.77$)$ and very poor agreement for the clinical data $\left(K^{\text {trans. }}\right.$ : $0.10 ; v_{e}: 0.16$; iAUGC: 0.21$)$.

Conclusion. Significant errors were found in the calculated DCE-MR imaging pharmacokinetic parameters for the perfusion analysis SPs, resulting in poor inter-software reproducibility.

\section{Keywords}

DCE-MRI, quantitative parameters, Tofts model, inter-software variability, simulated images, rectal cancer 


\section{INTRODUCTION}

As a non-invasive technique providing information on tumor microcirculation, $\mathrm{T}_{1}$-weighted dynamic contrast-enhanced (DCE) magnetic resonance (MR) imaging has been investigated in various clinical applications and perfusion parameters recognized as potential biomarkers of early therapeutic response (1-3). Their value has notably been reported in the assessment of locally advanced rectal cancer response to chemo-radiotherapy (4-8).

In order to establish a quantitative analysis of DCE-MRI acquisitions, Tofts and Kermode proposed a one-compartment perfused tissue model (9) that has become standard (10). This model relates the MR signal measured in the tissue of interest over time to two pharmacokinetic parameters: a volume transfer constant $K^{\text {trans }}\left(\mathrm{min}^{-1}\right)$ and an extravascular extracellular volume fraction $v_{e}$. Additionally, a rate constant $k_{e p}$ corresponds to the ratio $K^{\text {trans }} / v_{e}$. (11). Another common DCE-MR imaging-derived parameter is the initial area under the gadolinium curve (iAUGC, mmol. $\left.\mathrm{L}^{-1} \cdot \mathrm{min}\right)$. This is a model free, semi-quantitative approach that also requires conversion of voxel signal intensity to gadolinium concentration (12).

However, these quantitative methods can be affected by many sources of variation, including the strength and uniformity of the main static magnetic field $\left(B_{0}\right)$ and the radiofrequency field $\left(B_{1}\right)$, the chosen sequence (13), the temporal resolution (14), the pre-injection $\mathrm{T}_{1}$ relaxation time $\left(\mathrm{T}_{1,0}\right)$ calculation (15), the estimation of the arterial input function (AIF) (16), and the region of interest (ROI) selection in the tumor (17). These variations may compromise inclusion of DCE-MR imaging in multicenter clinical trials and clinical practice (18).

Literature reporting the impact of variations on the analysis of DCE-MR imaging due to software packages (SPs) is rare. Heye et al. showed considerable variability in 
pharmacokinetic parameters between four perfusion analysis SPs on uterine fibroid data although additional variation may have been introduced by the use of two ROI methods and five observers (19). Moreover, the "true" pharmacokinetic parameters in clinical data are unknown because they are composite parameters with no direct physiological, histological or immunohistochemical equivalent (20). Producing simulated data with a known "ground truth" is therefore of value as it could be used to investigate accuracy among analysis SPs.

The purpose of this study was to test the reproducibility and accuracy of pharmacokinetic parameter measurements on five analysis SPs for DCE-MR imaging, using both simulated and clinical data.

This study was designed to test the hypothesis that analysis SPs do not cause variation or bias in Tofts model and semi-quantitative pharmacokinetic parameter measurements. 


\section{MATERIALS AND METHODS}

Institutional review board approval was obtained for this ancillary study of the GRECCAR 4 trial (ClinicalTrials.gov identifier NCT0133709).

\section{Subjects and Perfusion Acquisition}

Twenty-seven consecutive patients (22 males, 5 females, mean age 62 years, range 31-82), screened in our institution for the GRECCAR 4 study investigating early response to chemotherapy in locally advanced rectal cancer, were included in this ancillary study. The main inclusion criteria were a histologically proven rectal adenocarcinoma and extramural extension on initial MR imaging. Thirty-six MR acquisitions (27 before treatment, 9 after chemotherapy) were performed between November 2012 and February 2014 on a 3T wholebody system (Magnetom Verio, Siemens Healthcare, Erlangen, Germany). DCE-MR imaging consisted of a dynamic pre- and post-contrast $\mathrm{T}_{1}$-weighted, three-dimensional spoiled gradient-echo sequence (Volume Interpolated Breath-hold Examination, VIBE) whose parameters were: matrix 192x192, field of view $240 \times 240 \mathrm{~mm}^{2}$, slice width $3 \mathrm{~mm}$, repetition time (TR) $4.1 \mathrm{~ms}$, echo time (TE) $1.4 \mathrm{~ms}$, flip angle $15^{\circ}, 24$ slices, temporal resolution of 5.2 $\mathrm{s}$ for an acquisition time of 3.5, 4.5 or 6 minutes, i.e. respectively 40,52 or 70 dynamics. A bolus of gadolinium-DOTA (0.1 mmol/kg, Dotarem; Guerbet, Villepinte, France) was injected into an antecubital vein. In addition, dual-flip-angle $\left(2^{\circ}\right.$ and $\left.15^{\circ}\right)$ pre-contrast $T_{1}$ mapping was performed. All data were stored in a research-dedicated server and could be retrieved retrospectively. On each examination, the slice on which the tumor section was the largest and most easily identifiable was selected by a radiologist (L.B., 4th-year radiology resident). A region of interest was drawn around all the tumor section on this slice, verified by 
a radiologist with 7 years of experience in rectal cancer evaluation (V.B.) and saved in the research-dedicated server.

The generation of cross-vendor clinical and simulated evaluation data is illustrated in Figure 1 and detailed below.

\section{Generation of Cross-vendor Evaluation Data}

Some SPs provided by MR scanner vendors do not allow analysis of DCE-MR images acquired on the scanners of rival vendors. To overcome this limitation, additional DCE-MRI acquisitions were performed on a General Electric Signa 1.5T (GE Healthcare, Milwaukee, WI) and a Philips Ingenia 3T scanner (Philips Healthcare, Best, the Netherlands) using a physical phantom (water container). The purpose of these new acquisitions was only to substitute these images with clinical images obtained on the 3T Verio system. Acquisition parameters were standardized to obtain the same spatial and temporal resolutions, TR, TE, flip angle, and slice thickness as on the reference Verio scan. In cases where the parameters could not be adjusted during the acquisition (e.g. $\mathrm{B}_{0}$ magnetic field strength) the DICOM header was edited with a batch DICOM metadata editor (DicomBrowser v 1.5.2, K. Archie, Neuroinformatics Research Group, 2012).

A Mathematica-based software (Wolfram Research Inc., version 8.0.1.0, Champaign, IL) was developed to substitute phantom images acquired on the Signa and Ingenia systems with clinical images acquired on the Verio scanner, without changing the Dicom header.

\section{Generation of Simulated Data}

Simulated data were created in order to test the accuracy of each SP. We adapted a program written by D. Barboriak et al. (21) that ran in JSim, an open-source modeling system (22). This program simulated the Tofts model as it follows: 


$$
\frac{d C_{t i s}}{d t}=K^{\text {trans }}\left(C_{p}-\frac{C_{t i s}}{v_{e}}\right)
$$

where $C_{\text {tis }}$ is the concentration of contrast agent in the simulated tissue and $C_{p}$ is the concentration in the blood plasma approximated by the arterial input function $(9,14)$. The variation of longitudinal relaxation time $T_{1}$ of the simulated tissue or plasma due to the contrast media is as follows:

$$
C=\frac{1}{\mathrm{r}_{1}} \times\left(\frac{1}{\mathrm{~T}_{1}}-\frac{1}{\mathrm{~T}_{1,0}}\right)
$$

where $C$ is the concentration of contrast media, $\mathrm{r}_{1}$ its longitudinal relaxivity and $\mathrm{T}_{1,0}$ the baseline $\mathrm{T}_{1}$ (before injection of the contrast media) (11).

The program also simulated the spoiled gradient-echo MR sequence signal $S$ corresponding to the simulated tissue:

$$
\mathrm{S}=\mathrm{S}_{0} \frac{\left(1-\mathrm{e}^{-\frac{\mathrm{TR}}{\mathrm{T}_{1}}}\right) \sin \alpha}{1-\mathrm{e}^{-\frac{\mathrm{TR}}{\mathrm{T}_{1}}} \cos \alpha}
$$

where TR denotes the repetition time, $\alpha$ is the flip angle, and $\mathrm{S}_{0}$ denotes the equilibrium magnetization holding to the assumption that $\mathrm{TE}<\mathrm{T} 2 *(23)$.

The longitudinal relaxivity $r_{1}$ of the contrast media was set to $3.9 \mathrm{mmol}^{-1} \cdot \mathrm{s}^{-1}\left(\mathrm{r}_{1}\right.$ relaxivity at $37^{\circ} \mathrm{C}$ and $3 \mathrm{~T}$ of Dotarem ${ }^{\mathrm{TM}}$ in human plasma) (24), the blood longitudinal time of relaxation $\mathrm{T}_{1,0}$ to $1.6 \mathrm{~s}(25)$.

Eighteen theoretical DCE-MR tissue signal curves were generated using different combinations of $K^{\text {trans }}\left(0.2,0.4,0.6 \mathrm{~min}^{-1}\right), v_{e}(0.2,0.4,0.6)$ and baseline longitudinal relaxation time $\mathrm{T}_{1,0}(800,1000 \mathrm{~ms})$. A population arterial input function was used for the simulation (21) and saved as a nineteenth signal curve, constituting the signal of a simulated artery voxel. 
We developed a second Mathematica-based software to convert these curves into pixel clusters for three Gaussian noise levels (zero, mild [1\% standard deviation] and strong [10\% standard deviation]) and insert them into DICOM dynamic images (Figure 1b). Pixel clusters of a theoretical signal corresponding to the $\mathrm{T}_{1,0}$ of the tissues were also inserted into variable flip angle sequences.

\section{Perfusion Data Postprocessing}

The DCE-MR imaging postprocessing SPs evaluated in this study included three proprietary SPs (Table 1): syngo.MR Tissue 4D v.40A (Siemens Healthcare, Erlangen, Germany) [A], Advantage Windows GenIQ v.11.3 (GE Healthcare, Milwaukee, WI) [B], IntelliSpace Portal T1 Permeability v.6.0.1 (Philips Healthcare, Best, the Netherlands) [C]; and two academic plugins running in OsiriX (v.5.8.1, University Hospital of Geneva, Switzerland (26)): DCE Tool (v.2.0, K. Sung, UCLA, http://kyungs.bol.ucla.edu) [D] and UMM perfusion (v.1.5.1, F. Zöllner et al., University of Mannheim, Germany (27)) [E]. The DCE-MRI examinations with clinical images and those with simulated inserted data were transferred to each SP. One unblinded observer (L.B.) measured pharmacokinetic parameters on each SP, with the following approach regarding software options:

- use of the Tofts model (or, if unavailable, the extended Tofts model that also calculates $v_{p}$, the plasmatic volume fraction)

- $\quad$ use of a patient-based AIF was preferred if available: an ROI was drawn in the left common femoral artery when postprocessing clinical data and in the simulated artery voxels when analyzing simulated data;

- if the time to peak was not automatically determined, the same value was input into each SP for each patient; 
- if the software did not incorporate $T_{1,0}$ mapping but required a reference value corresponding to the tissue of interest the "Soft tissue" value (900 ms) was input;

- the iAUGC was set to the area under the gadolinium curve for 60 seconds after the bolus peak;

- no motion correction was applied.

Parametric maps of $K^{\text {trans }}, v_{e}, k_{e p}$ and iAUGC were exported and transferred to a centralized database. Sets of previously saved ROIs were applied to each parametric map in order to avoid measurement variability due to ROI positioning (28).

\section{Validation of the image data manipulation}

Extensive software manipulation of the image data was necessary so the same datasets could be evaluated with SPs from different vendors. To confirm that this manipulation was valid and did not introduce variability of its own, the original set of images acquired from one patient on the Verio scanner and the examinations acquired on the Signa and Ingenia systems in which the Verio images had been inserted were post processed with the same cross platform SP (DCE Tool). Same values of $K^{\text {trans }}, v_{e}, k_{e p}$ and iAUGC were obtained for the three sets of images.

\section{Statistical Analysis}

Statistical analyses were performed using PASW Statistics (v.19.0, SPSS, Chicago, IL).

\section{Simulated Data}

A Bland-Altman analysis was conducted, measuring the difference between the value of a parameter measured by an SP and its simulated "true" value (29). Bias and dispersion correspond to the average and standard deviation of these differences, respectively. Intraclass 
correlation coefficients (ICCs) and their 95\% confidence intervals were calculated to determine the absolute agreement of pharmacokinetic parameter output among SPs.

\section{Clinical Data}

A Bland-Altman analysis was conducted, measuring the difference between the value of a parameter measured by SP X and the one measured by SP Y. ICCs were also calculated, and the test-retest root mean square coefficient of variation method (30) was applied to obtain the within-subject coefficient of variation for a pairwise comparison of all SP combinations.

\section{Ratio tumor / simulated reference tissue}

For each patient and each software package, the ratio between the pharmacokinetic parameters extracted from the ROI drawn over the tumor and those extracted from the ROI drawn over one simulated tissue (Ktrans $=0.4, \mathrm{ve}=0.4, \mathrm{~T} 1,0=1000 \mathrm{~ms}$, no noise $)$, constituting a reference tissue, was calculated. Then, intraclass correlation coefficients for each pharmacokinetic parameter ratio among the different SPs were calculated. 


\section{RESULTS}

\section{Simulated Data}

Fifty-four pixel clusters, corresponding to 18 combinations of $K^{\text {trans }} / v_{e} / \mathrm{T}_{1,0}$ values at three noise levels, were successfully fed into the dynamic MR images acquired on the three scanners and processed with the five SPs. The iAUGC of simulated tissues was in the range of 14.8-44.5 mmol. $\mathrm{L}^{-1} . \mathrm{min}\left(\right.$ mean $27.2 \mathrm{mmol} . \mathrm{L}^{-1} . \mathrm{min}$, standard derivation $\left.9.5 \mathrm{mmol} . \mathrm{L}^{-1} . \mathrm{min}\right)$. All measurements are provided in Appendix 1 and graphically plotted in Figure 2. Details of all statistical tests are given in the tables and figures. The most significant results are reported below.

\section{Bland-Altman Analysis}

A graphical representation of the Bland-Altman analysis is given in Figure 3, illustrating the accuracy of SPs for measuring the pharmacokinetic parameters. SPs A, B and D tended to underestimate $K^{\text {trans }}$ (bias: $-0.13,-0.05$ and $-0.19 \mathrm{~min}^{-1}$, respectively), especially for high $K^{\text {trans }}$ values, whereas SPs C and E slightly overestimated it (bias: 0.03 and $0.09 \mathrm{~min}^{-1}$, respectively). SPs A, D and E underestimated $v_{e}$ (bias: $-0.10,-0.13$ and $-0.15 \mathrm{~min}^{-1}$, respectively) and there was a wide dispersion of values measured by all the SPs (range 0.030.8). SPs A and D measured iAUGC accurately but there was a wide dispersion of values measured by SPs B and C (5.05 and $8.17 \mathrm{mmol} . \mathrm{L}^{-1} . \mathrm{min}$, respectively).

\section{Correlation Analysis}

The ICCs for testing absolute agreement between SPs in terms of pharmacokinetic parameters are given in Table 2, reflecting inter-software reproducibility. ICCs ranged from 0.50 for $K^{\text {trans }}$ to 0.77 for iAUGC. Subanalyses of repeatability considering potential sources of 
variation among the SPs (excluding the SPs applying a different physiological model than Tofts model, not allowing for variable T1 mapping, or using a population based arterial input function) did not show significantly different values.

The measurements on noiseless, low-noise and high-noise image sets were very similar, with an intraclass correlation coefficient between the calculated pharmacokinetic parameters at different levels of noise equal to 0.99 .

\section{Clinical Data}

Five examinations (from four patients) were rejected: two of them because the cancer involved the anal canal, one due to an error in the slice orientation of the DCE-MR acquisition, and two due to severe artifacts caused by hip prostheses. Thirty one examinations were thus post processed. Among them, four could not be processed by SP C due to errors in variable flip angle sequences positioning. Mean tumor size was $6.8 \mathrm{~cm}^{2}$, ranging from 1.9 to $24.4 \mathrm{~cm}^{2}$, and mean tumor $\mathrm{T}_{1,0}$ measured by the DCE Tool was $1201 \mathrm{~ms}$, ranging from 423 to 2280 ms. All measurements are provided in Appendix 2 and graphically plotted in Figure 4.

\section{Bland-Altman Analysis}

The Bland-Altman plots in Figure 5 show the differences in agreement between SPs.

Dispersion was significant in all comparisons for all the pharmacokinetic parameters. $K^{\text {trans }}$ values returned by SP A were lower than values returned by all the other SPs, whereas all parameters values returned by SP B were higher than those returned by other SPs, except for $K^{\text {trans }}$ values when compared to SP E. Concerning the iAUGC measurements, the best agreement was observed between SPs A and D (bias: -3.48 mmol. $\mathrm{L}^{-1}$.min, dispersion: 7.69 $\left.\mathrm{mmol} \cdot \mathrm{L}^{-1} \cdot \mathrm{min}\right)$. 
Correlation Analysis

The ICCs (Table 2) showed very poor agreement between SPs for all the pharmacokinetic parameters concerning clinical data, ranging from 0.10 for $K^{\text {trans }}$ to 0.21 for iAUGC.

Subanalyses based on the SPs features did not show significantly better reproducibility, as for the ratios between the pharmacokinetic parameters extracted from the ROI drawn over the tumor and those extracted from a reference simulated tissue.

\section{Variation Analysis}

Within-subject coefficients of variation for all SP comparisons (Table 3) were always above 0.20, except when comparing the iAUGC measurements provided by SPs A and D (0.19).

They ranged from 0.40 to 0.88 for $K^{\text {trans }}, 0.27$ to 0.47 for $v_{e}, 0.35$ to 0.92 for $k_{e p}$, and 0.19 to 0.76 for iAUGC. 


\section{DISCUSSION}

Our results yielded significant errors in pharmacokinetic measurements for all the perfusion analysis SPs when postprocessing simulated data, leading to substantial inter-software variability. Inter-SP reproducibility was worse when dealing with clinical data.

The within-subject variation across SPs found in our study, ranging from $40 \%$ to $88 \%$ for $K^{\text {trans }}$, was higher than the upper limit of $20 \%$ which is the goal of current quantitative imaging initiatives (18). It exceeded the $40 \% K^{\text {trans }}$ decrease between pre- and postchemoradiotherapy found by Kim et al. to be associated with rectal tumor downstaging when using a single perfusion analysis SP (5). Considering that the difference between mean $K^{\text {trans }}$ values after chemotherapy among patients with or without complete pathological response is about $0.3 \mathrm{~min}^{-1}$, according to Gollub et al. (4), the limits of agreement observed in our study are considerably wider and therefore a potential source of error when assessing patient prognosis.

A large proportion of the observed variation may be explained by the different methods of $\mathrm{T}_{1,0}$ relaxation time estimation. Some SPs computed parametric maps from $\mathrm{T}_{1}$-weighted variable flip-angle sequences whereas others used reference values from the literature or requested user input. Applying set $\mathrm{T}_{1,0}$ times across an entire heterogeneous lesion including areas of necrosis is a potential source of error (31). The $\mathrm{T}_{1,0}$ values measured in the clinical lesions had a much wider range than the $800 \mathrm{~ms}$ and $1000 \mathrm{~ms}$ values used in our simulated data, which were closer to the soft tissue reference value of $900 \mathrm{~ms}$ (25). This wide spectrum of $\mathrm{T}_{1,0}$ values in the tumor, whether real or overestimated by the variable flip-angle method of 
calculation, could provide an initial explanation for the greater variability seen in the pharmacokinetic parameters calculated from clinical data as compared to the simulated data.

Another source of variation may be the arterial input function. Most SPs proposed a patientbased AIF, asking the user to draw an ROI in an artery on the dynamic acquisition, whereas SP A only used a population-based AIF. Vascular peak characterization was automatic in two SPs and user-defined in the other SPs. This should mainly affect calculation of $K^{\text {trans }}$, which reflects the earlier phases of the enhancement curve whereas $v_{e}$ correlates with the later phases (16), and could explain the greater variability of $K^{\text {trans }}$ as compared to $v_{e}$ in our measurements. Lastly, although this information was not always available in the SP documentation, it is probable that their curve-fitting algorithms were different, leading to differences in pharmacokinetic parameter output (32).

The iAUGC measurement errors for SP C are surprising despite calculation of a parametric $\mathrm{T}_{1,0}$-map. The only source of error should arise from signal conversion to gadolinium concentration. Our theory is that this software does not integrate the measured data curve but its fit according to the Tofts model. Errors in curve adjustment according to $K^{\text {trans }}$ and $v_{e}$ could therefore bias calculation of iAUGC.

Heye et al. previously showed considerable variability for DCE-MR imaging pharmacokinetic parameter computation among SP [A] and four cross-platform perfusion analysis SPs on clinical data (19). Huang et al. also showed a wide variability in pharmacokinetic parameters between between several multicentric in-house SPs on breast cancer data (33). Our comparison of the three main MR vendor SPs confirmed this lack of reproducibility and our results on simulated data quantify the measurement errors of each SP. 
Using the same simulation tool but with lower $K^{\text {trans }}$ values, Cron et al. observed a high percentage of unphysical values when comparing the reaction of three DCE-MR analysis SPs to increasing noise levels (34). This study re-enforces the Quantitative Imaging Biomarkers Alliance profile recommendations that a single SP should be used for any longitudinal study or any static evaluation across a given population of patients (18).

This study had limitations. Concerning the simulated data, the choice of $K^{\text {trans }}$ values was partly empirical, since average measurements in the literature dealing with rectal cancer ranged from 0.2 to $2.1 \mathrm{~min}^{-1}(4,5,7)$. We chose lower values reflecting our clinical practice and associated with physiological enhancement curves. We considered that 1026 measurements on simulated data were sufficient to achieve statistical power but more combinations of pharmacokinetic parameters could have been used.

We could have used a faster temporal resolution in our simulated data, but this choice requires acquiring fewer slices, which is a limiting factor in a clinical context because it implies a smaller coverage of the tumor. Moreover, although the technical parameters of the DCE MR sequence were suboptimal, they were the same for each postprocessing SP and thus cannot be held responsible for the variability we observed.

Only one unblinded observer evaluated the postprocessing of simulated and clinical acquisitions, thus eliminating another measurement variability factor.

Also, an additional source of variability concerning clinical data may have been the organ of interest, i.e. rectal tumors, which can be affected by technical difficulties such as peristaltism. Nevertheless, the technique we used was approved by several authors (4-8) and concerns pharmacokinetic measurement reproducibility. Inability to access the source code of commercial SPs prevented any automation in the postprocessing process, possibly resulting in additional variability due to the user, but this reflected clinical practice. 
In conclusion, there are significant errors in calculated DCE-MR imaging pharmacokinetic parameters $\left(K^{\text {trans }}, v_{e}\right.$, iAUGC) among perfusion analysis SPs, resulting in poor inter-software reproducibility. There is a need for standardization to enable the use of DCE-MR imaging as a quantitative biomarker in multicenter trials and clinical practice. For now, a single SP should be used in a given study, in agreement with international recommandations, and absolute values of pharmacokinetic parameters provided in the literature should be viewed with caution. 


\section{ABBREVIATIONS}

$\mathrm{AIF}=$ arterial input function

DCE $=$ dynamic contrast-enhanced

DICOM $=$ digital imaging and communications in medicine

iAUGC $=$ initial area under the gadolinium curve

ICC $=$ intraclass correlation coefficient

$K^{\text {trans }}=$ volume transfer constant

$\mathrm{ROI}=$ region of interest

$\mathrm{SP}=$ software package

$v_{e}=$ extravascular extracellular volume fraction 


\section{REFERENCES}

1. Zahra MA, Hollingsworth KG, Sala E, Lomas DJ, Tan LT: Dynamic contrast-enhanced MRI as a predictor of tumour response to radiotherapy. Lancet Oncol 2007; 8:63-74.

2. Hylton N: Dynamic contrast-enhanced magnetic resonance imaging as an imaging biomarker. J Clin Oncol 2006; 24:3293-3298.

3. O'Connor JPB, Jackson A, Parker GJM, Jayson GC: DCE-MRI biomarkers in the clinical evaluation of antiangiogenic and vascular disrupting agents. Br J Cancer 2007; 96:189-195.

4. Gollub MJ, Gultekin DH, Akin O, et al.: Dynamic contrast enhanced-MRI for the detection of pathological complete response to neoadjuvant chemotherapy for locally advanced rectal cancer. Eur Radiol 2012; 22:821-831.

5. Kim SH, Lee JM, Gupta SN, Han JK, Choi BI: Dynamic contrast-enhanced MRI to evaluate the therapeutic response to neoadjuvant chemoradiation therapy in locally advanced rectal cancer. J Magn Reson Imaging 2013;40:730-7.

6. De Lussanet QG, Backes WH, Griffioen AW, et al.: Dynamic contrast-enhanced magnetic resonance imaging of radiation therapy-induced microcirculation changes in rectal cancer. Int J Radiat Oncol 2005; 63:1309-1315.

7. Lim JS, Kim D, Baek S-E, et al.: Perfusion MRI for the prediction of treatment response after preoperative chemoradiotherapy in locally advanced rectal cancer. Eur Radiol 2012; 22:1693-1700.

8. Kremser C, Trieb T, Rudisch A, Judmaier W, de Vries A: Dynamic T1 mapping predicts outcome of chemoradiation therapy in primary rectal carcinoma: Sequence implementation and data analysis. J Magn Reson Imaging 2007; 26:662-671.

9. Tofts PS, Kermode AG: Measurement of the blood-brain barrier permeability and leakage space using dynamic MR imaging. 1. Fundamental concepts. Magn Reson Med 1991; 17:357367.

10. Sourbron SP, Buckley DL: On the scope and interpretation of the Tofts models for DCEMRI. Magn Reson Med 2011; 66:735-745.

11. Tofts PS, Brix G, Buckley DL, et al.: Estimating kinetic parameters from dynamic contrast-enhanced $\mathrm{t} 1$-weighted MRI of a diffusable tracer: Standardized quantities and symbols. J Magn Reson Imaging 1999; 10:223-232.

12. Yeo D-M, Oh SN, Jung C-K, et al.: Correlation of dynamic contrast-enhanced MRI perfusion parameters with angiogenesis and biologic aggressiveness of rectal cancer: Preliminary results. J Magn Reson Imaging 2013;41:474-80.

13. Bergamino M, Bonzano L, Levrero F, Mancardi GL, Roccatagliata L: A review of technical aspects of T1-weighted dynamic contrast-enhanced magnetic resonance imaging (DCE-MRI) in human brain tumors. Phys Med 2014;30:635-43. 
14. Tofts PS: T1-weighted DCE imaging concepts: modelling, acquisition and analysis. MAGNETOM Flash Ed RSNA 2010:30-39.

15. Tofts PS, Berkowitz B, Schnall MD: Quantitative analysis of dynamic Gd-DTPA enhancement in breast tumors using a permeability model. Magn Reson Med 1995; 33:564568.

16. Cuenod CA, Balvay D: Perfusion and vascular permeability: Basic concepts and measurement in DCE-CT and DCE-MRI. Diagn Interv Imaging 2013; 94:1187-1204.

17. Preda A, Turetschek K, Daldrup H, et al.: The choice of region of interest measures in contrast-enhanced magnetic resonance image characterization of experimental breast tumors. Invest Radiol 2005; 40:349-354.

18. QIBA: DCE-MRI Technical Committee. DCE-MRI Quantification Profile, Quantitative Imaging Biomarkers Alliance. Version 1.0. Publicly Reviewed Version. 2012.

19. Heye T, Davenport MS, Horvath JJ, et al.: Reproducibility of dynamic contrast-enhanced MR imaging. Part I. Perfusion characteristics in the female pelvis by using multiple computeraided diagnosis perfusion analysis solutions. Radiology 2013; 266:801-811.

20. Kim Y-E, Lim JS, Choi J, et al.: Perfusion parameters of dynamic contrast-enhanced magnetic resonance imaging in patients with rectal cancer: correlation with microvascular density and vascular endothelial growth factor expression. Korean J Radiol 2013; 14:878885 .

21. Barboriak DP, MacFall JR, Viglianti BL, Dewhirst MW: Comparison of Three Physiologically-Based Pharmacokinetic Models for the Prediction of Contrast Agent Distribution Measured by Dynamic MR Imaging. J Magn Reson Imaging 2008; 27:13881398.

22. Butterworth E, Jardine BE, Raymond GM, Neal ML, Bassingthwaighte JB: JSim, an open-source modeling system for data analysis. F1000Research 2013; 2:288.

23. Chung J, Kim J-H, Lee EJ, Kim YN, Yi CA: Semiautomatic Determination of Arterial Input Functions for Quantitative Dynamic Contrast-Enhanced Magnetic Resonance Imaging in Non-Small Cell Lung Cancer Patients. Invest Radiol 2014;50(3):129-34.

24. Vander Elst L, Raynaud J-S, Vives V, et al.: Comparative Relaxivities and Efficacies of Gadolinium-based Commercial Contrast Agents. Proceedings of the 21st Annual Meeting of ISMRM, Salt Lake City 2013 (abstract 0746).

25. De Bazelaire CMJ, Duhamel GD, Rofsky NM, Alsop DC: MR imaging relaxation times of abdominal and pelvic tissues measured in vivo at 3.0 T: preliminary results. Radiology 2004; 230:652-659.

26. Rosset A, Spadola L, Ratib O: OsiriX: an open-source software for navigating in multidimensional DICOM images. J Digit Imaging 2004; 17:205-216. 
27. Zöllner FG, Weisser G, Reich M, et al.: UMMPerfusion: an open source software tool towards quantitative MRI perfusion analysis in clinical routine. J Digit Imaging 2013; $26: 344-352$.

28. Braunagel M, Radler E, Ingrisch M, et al.: Dynamic contrast-enhanced magnetic resonance imaging measurements in renal cell carcinoma: effect of region of interest size and positioning on interobserver and intraobserver variability. Invest Radiol 2015; 50:57-66.

29. Bland JM, Altman DG: Statistical methods for assessing agreement between two methods of clinical measurement. Lancet 1986; 1:307-310.

30. Roberts C, Issa B, Stone A, Jackson A, Waterton JC, Parker GJM: Comparative study into the robustness of compartmental modeling and model-free analysis in DCE-MRI studies. $J$ Magn Reson Imaging 2006; 23:554-563.

31. Heye T, Boll DT, Reiner CS, Bashir MR, Dale BM, Merkle EM: Impact of precontrast T10 relaxation times on dynamic contrast-enhanced MRI pharmacokinetic parameters: T10 mapping versus a fixed T10 reference value. J Magn Reson Imaging 2014; 39:1136-1145.

32. Murase K: Efficient method for calculating kinetic parameters using T1-weighted dynamic contrast-enhanced magnetic resonance imaging. Magn Reson Med 2004; 51:858862.

33. Huang W, Li X, Chen Y, et al. Variations of dynamic contrast-enhanced magnetic resonance imaging in evaluation of breast cancer therapy response: a multicenter data analysis challenge. Transl Oncol. 2014 Feb;7:153-66.

34. Cron GO, Sourbron SP, Barboriak DP, Abdeen R, Hogan M, Nguyen TB: Bias and precision of three different DCE-MRI analysis software packages: a comparison using simulated data. Proceedings of the 22nd Annual Meeting of ISMRM, Milan 2014 (abstract 4592). 
TABLES

TABLE 1. Main Characteristics of DCE-MR Imaging Postprocessing SPs

\begin{tabular}{|c|c|c|c|c|c|}
\hline Characteristics & Tissue 4D [A] & GenIQ [B] & T1 permeability $[\mathrm{C}]$ & DCE Tool [D] & UMM perfusion [E] \\
\hline Developer & Siemens & General Electric & Philips & K Sung, UCLA & $\begin{array}{l}\text { F Zöllner, G Weisser, } \\
\text { Mannheim University }\end{array}$ \\
\hline Platform & Syngo & Advantage Windows & IntelliSpace Portal & OsiriX & OsiriX \\
\hline License & Proprietary & Proprietary & Proprietary & Free & Open source \\
\hline Pharmacokinetic model & Tofts & Tofts, extended Tofts & Extended Tofts & Tofts, extended Tofts & $\begin{array}{l}\text { Tofts, extended Tofts, } \\
2 \text { compartment exchange, } \\
2 \text { compartment filtration, } \\
2 \text { compartment uptake }\end{array}$ \\
\hline $\mathrm{T}_{1}$ relaxation time estimation & $\begin{array}{l}\text { Variable flip angle } \\
\text { map or user input }\end{array}$ & $\begin{array}{c}\text { Reference value } \\
\text { according to } \\
\text { anatomical } \\
\text { localization }\end{array}$ & $\begin{array}{l}\text { Variable flip angle } \\
\text { map }\end{array}$ & $\begin{array}{l}\text { Variable flip angle } \\
\text { map or user input }\end{array}$ & None \\
\hline Arterial Input Function & Population based & $\begin{array}{c}\text { Population or patient } \\
\text { based }\end{array}$ & $\begin{array}{l}\text { Population or patient } \\
\text { based }\end{array}$ & $\begin{array}{l}\text { Population or patient } \\
\text { based }\end{array}$ & $\begin{array}{l}\text { Population or patient } \\
\text { based }\end{array}$ \\
\hline Time to peak measurement & User input & Automatic & Automatic & User input & User input \\
\hline Motion correction and registration & Possible & Possible & No & No & No \\
\hline
\end{tabular}


Table 2. ICCs or Absolute Agreement Between SPs For Pharmacokinetic Parameters

\section{Pharmacokinetic parameter}

Simulated Tissues

\section{Clinical Data}

SP type

\section{All}

SPs applying Tofts model (excluding [C])

SPs allowing for variable T1 mapping ([A],[C], [D])

SPs with patient based arterial input function (excluding [A])

All - ratio tumor / simulated reference tissue

$v_{e}$

\section{All}

SPs applying Tofts model (excluding [C])

SPs allowing for variable T1 mapping ([A],[C], [D])

SPs with patient based arterial input function (excluding [A])

All - ratio tumor / simulated reference tissue

$\boldsymbol{k}_{e p}$

\section{All}

SPs applying Tofts model (excluding [C])

SPs allowing for variable T1 mapping ([A],[C], [D])

SPs with patient based arterial input function (excluding [A])

All - ratio tumor / simulated reference tissue

\section{iAUGC}

All

SPs applying Tofts model (excluding [C])

SPs allowing for variable T1 mapping ([A],[C], [D])

SPs with patient based arterial input function (excluding [A]

All - ratio tumor / simulated reference tissue

ICC $\quad 95 \%$ CI

ICC

95\% CI

$\begin{array}{ll}\mathbf{0 . 5 0} & \mathbf{0 . 2 3}-\mathbf{0 . 7 0} \\ 0.43 & 0.14-0.65 \\ 0.47 & 0.04-0.74 \\ 0.51 & 0.19-0.73\end{array}$

0.10

$0.01-0.25$

0.12

$0-0.29$

0.10

$-0.6-0.33$

0.13

$0-0.32$

0.11

$0.02-0.27$

$\begin{array}{ll}\mathbf{0 . 6 7} & \mathbf{0 . 3 8}-\mathbf{0 . 8 2} \\ 0.64 & 0.30-0.81 \\ 0.76 & 0.22-0.91 \\ 0.63 & 0.28-0.81\end{array}$

0.16

$0.04-0.35$

0.23

$0.07-0.43$

0.21

$-0.01-0.47$

0.14

$0-0.35$

0.14

$0.03-0.30$

0.55

$0.29-0.73$

0.11

$0.01-0.28$

0.46

$0.17-0.67$

0.12

$0-0.28$

0.82

$0.57-0.91$

0.13

$-0.03-0.35$

0.55

$0.23-0.75$

0.15

$0.01-0.34$

0.13

$0.02-0.29$

$\begin{array}{ll}\mathbf{0 . 7 7} & \mathbf{0 . 6 9}-\mathbf{0 . 8 5} \\ 0.90 & 0.84-0.94 \\ 0.77 & 0.66-0.85 \\ 0.72 & 0.61-0.82\end{array}$

0.21

$0.02-0.44$

0.27

$0.01-0.53$

0.44

$0.12-0.69$

0.16

$-0.02-0.41$

0.20

$0.03-0.42$

ICC $=$ intraclass correlation coefficient; $\mathrm{CI}=$ confidence interval; $\mathrm{SPs}=$ software packages 
TABLE 3. Within-Subject Coefficients of Variation for All SP Comparisons

\begin{tabular}{lcccc}
\hline & $\boldsymbol{K}^{\text {trans }}$ & $\boldsymbol{v}_{\boldsymbol{e}}$ & $\boldsymbol{k}_{\boldsymbol{e} \boldsymbol{p}}$ & iAUGC \\
\hline A vs. B & 0.82 & 0.37 & 0.78 & 0.49 \\
A vs. C & 0.54 & 0.37 & 0.58 & 0.44 \\
A vs. D & 0.63 & 0.29 & 0.69 & 0.19 \\
A vs. E & 0.88 & 0.27 & 0.92 & - \\
B vs. C & 0.67 & 0.47 & 0.53 & 0.76 \\
B vs. D & 0.55 & 0.42 & 0.35 & 0.47 \\
B vs. E & 0.40 & 0.28 & 0.45 & - \\
C vs. D & 0.63 & 0.43 & 0.46 & 0.49 \\
C vs. E & 0.75 & 0.31 & 0.69 & - \\
D vs. E & 0.57 & 0.32 & 0.52 & - \\
\hline A. Tissue & &
\end{tabular}

A: Tissue 4D; B: GenIQ; C: T1 permeability; D: DCE Tool; E: UMM perfusion -: not available (iAUGC calculation is not available in UMM perfusion)

The test-retest root mean square coefficient of variation method was applied to obtain the within-subject coefficient of variation for a pairwise comparison of all SP combinations 


\section{FIGURE LEGENDS}

Fig. 1: Diagram of the process of software packages (SPs) comparison with clinical images and simulated data. Phantom images acquired on the GE and Philips scanners were substituted with clinical dynamic images acquired on the Siemens scanner, without changing the DICOM headers. Moreover, the banners with simulated pixel clusters were inserted into the dynamic images acquired on each scanner; the central cluster corresponds to the simulated artery, the other eighteen correspond to simulated tissues with different $K^{\text {trans }}, v_{e}$ and $\mathrm{T}_{1,0}$ combinations.

Fig. 2: Box plots of simulated tissue pharmacokinetic parameters according to perfusion analysis SPs (light gray) compared to their "true" simulated values (dark gray). The top and bottom box edges represent the 25 th and 75 th percentiles, respectively; horizontal central lines represent the median values; top and bottom whiskers represent the 10th and 90th percentiles, respectively; circled points represent outliers. The results pertain to the entire set of reference values.

Fig. 3: Bland-Altman analysis for simulated tissue pharmacokinetic parameters. $\diamond$ : bias (mean of the differences between the measured and simulated true value). Left and right ends of horizontal bars correspond to the lower and upper limits of agreement, respectively. The length of the horizontal bar is proportional to the dispersion.

Fig. 4: Box plots of clinical data pharmacokinetic parameters according to perfusion analysis SPs. The top and bottom box edges represent the 25 th and 75 th percentiles, respectively; horizontal central lines represent the median values; top and bottom whiskers represent the 10th and 90th percentiles, respectively; circled points represent outliers.

Fig. 5: Bland-Altman analysis for clinical data pharmacokinetic parameters. $\diamond$ : bias (mean of the differences between the measurements taken on each lesion by two SPs). Left and right 
ends of horizontal bars correspond to the lower and upper limits of agreement, respectively. The length of the horizontal bar is proportional to the dispersion. 


\section{MR acquisitions}
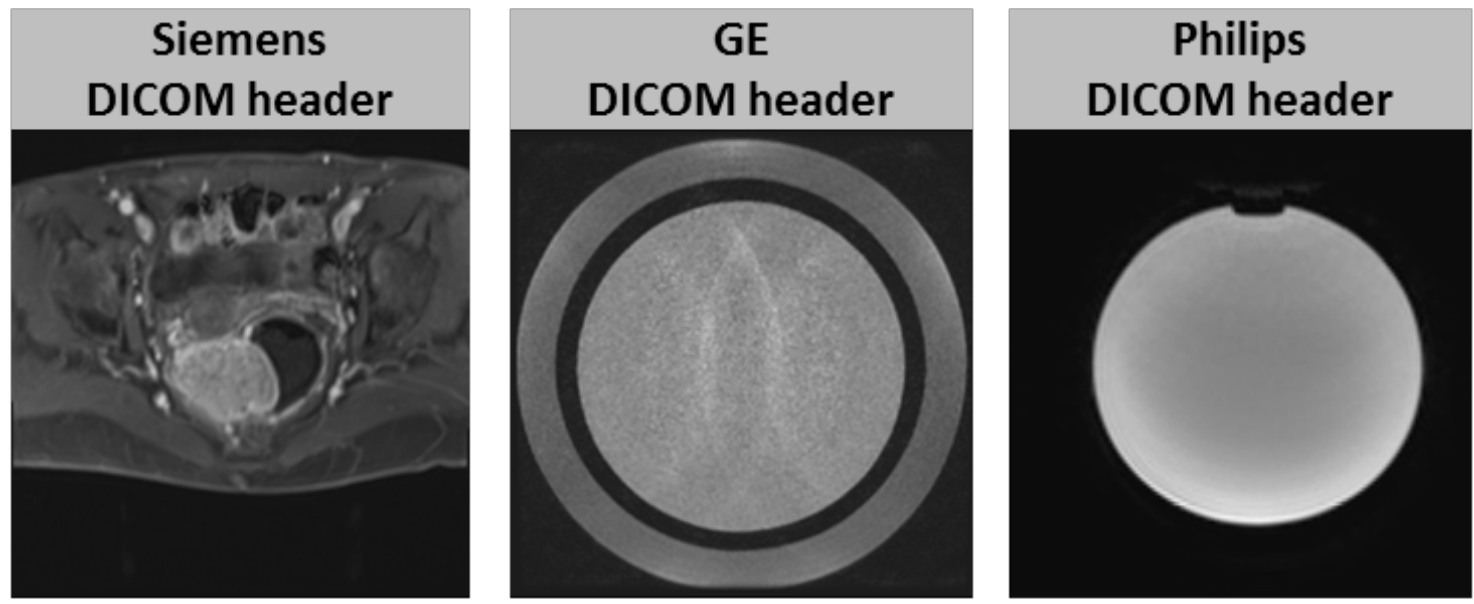

\section{Images substitutions and simulated data} insertions
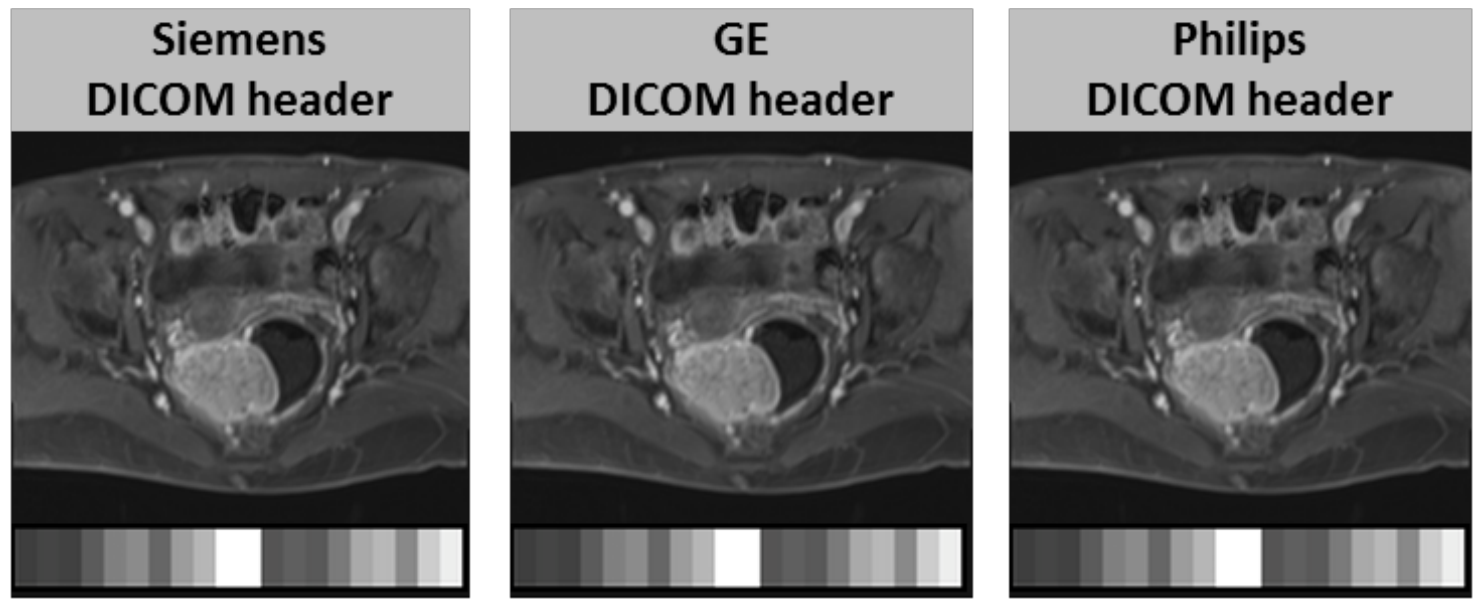

Post processing

SP A

SP D

SP B

SP C

SP E

Figure 1 


\section{min-1}

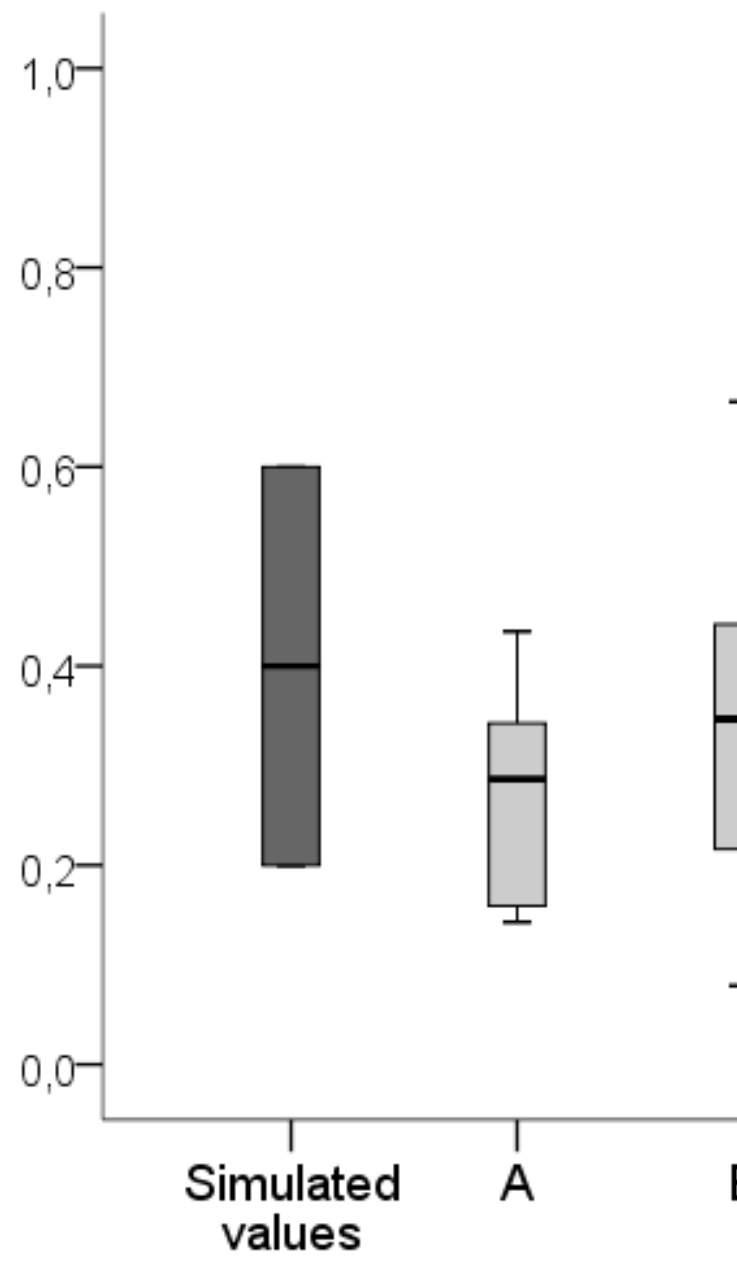

Ktrans
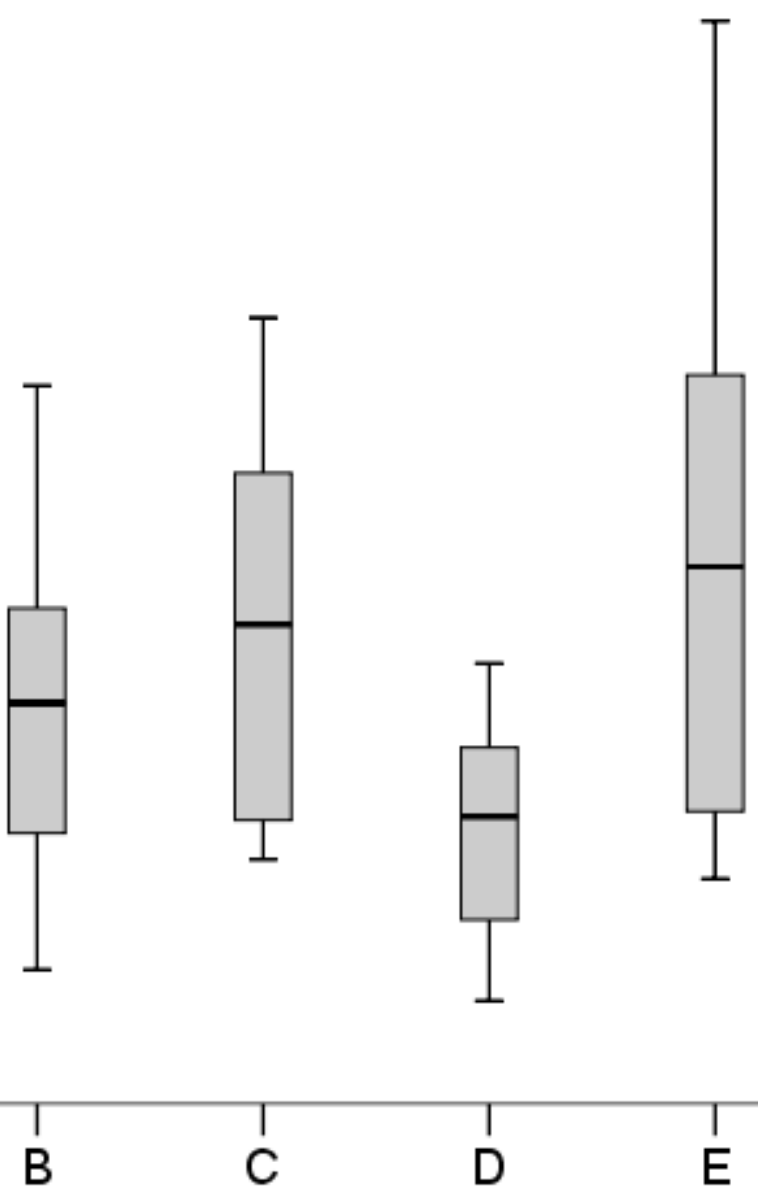

Figure 2 - a 


\section{Ve}

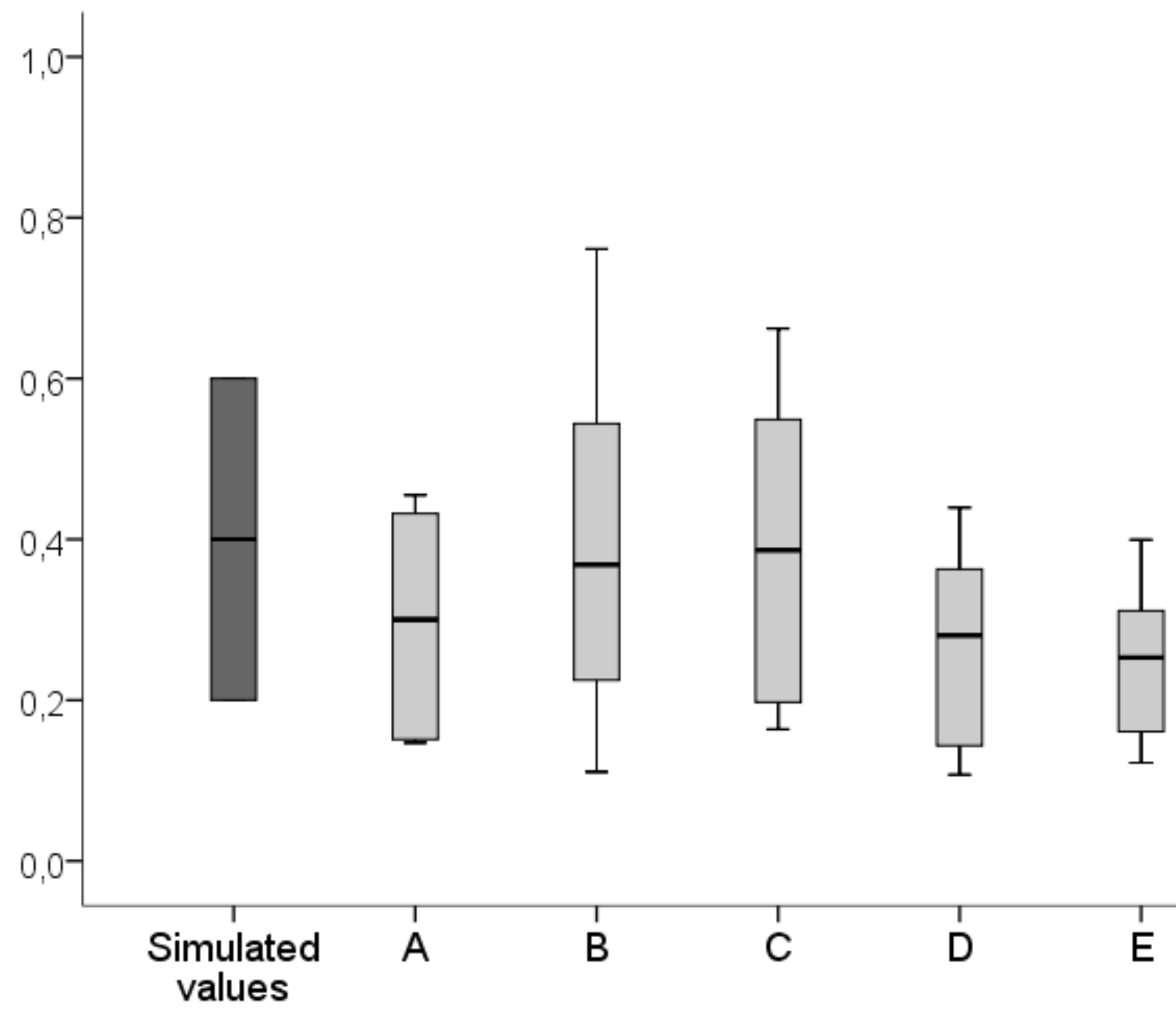

Figure 2 - b 


\section{Kep}

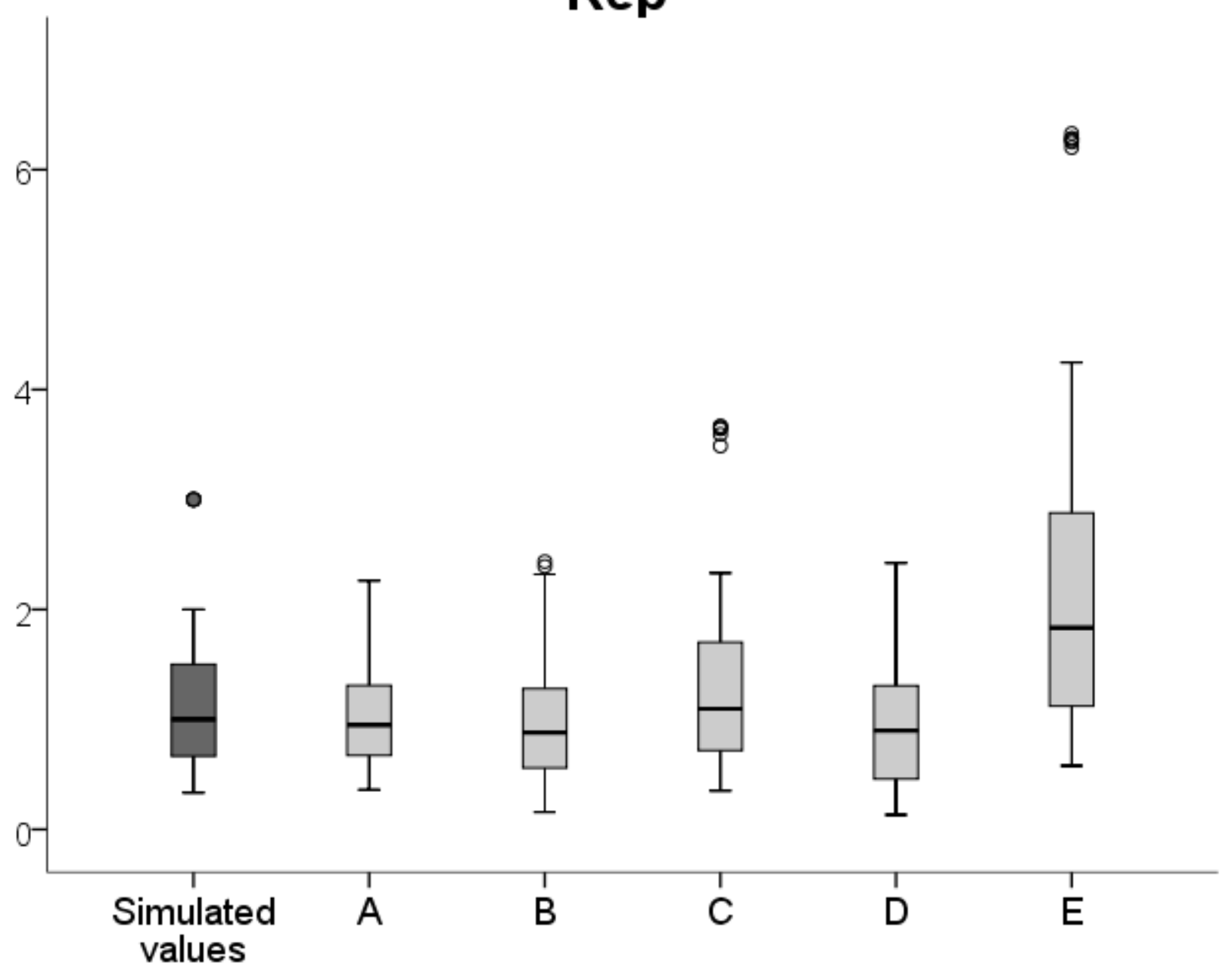

Figure 2 - c 
mmol.L-1.min

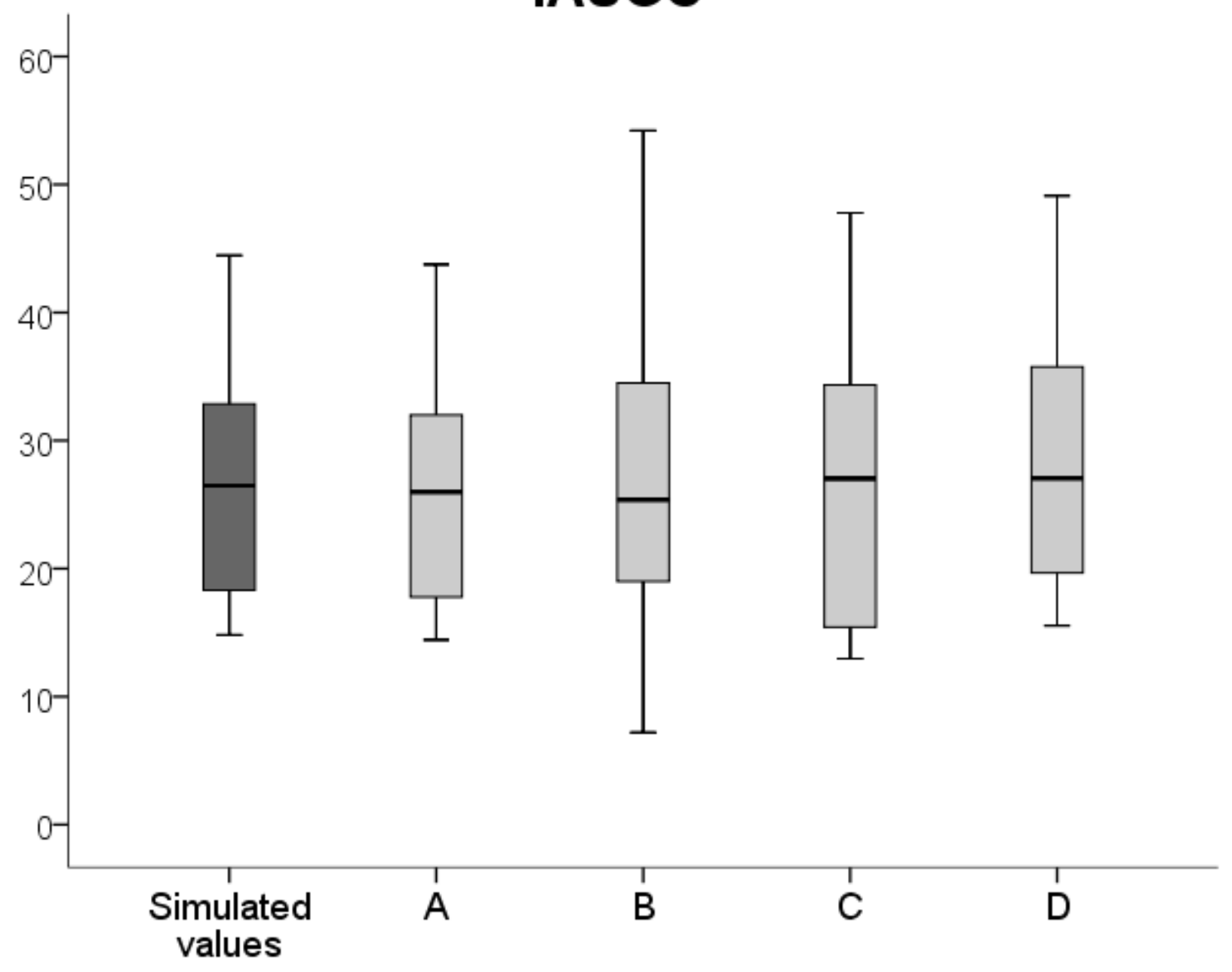

Figure 2-d 


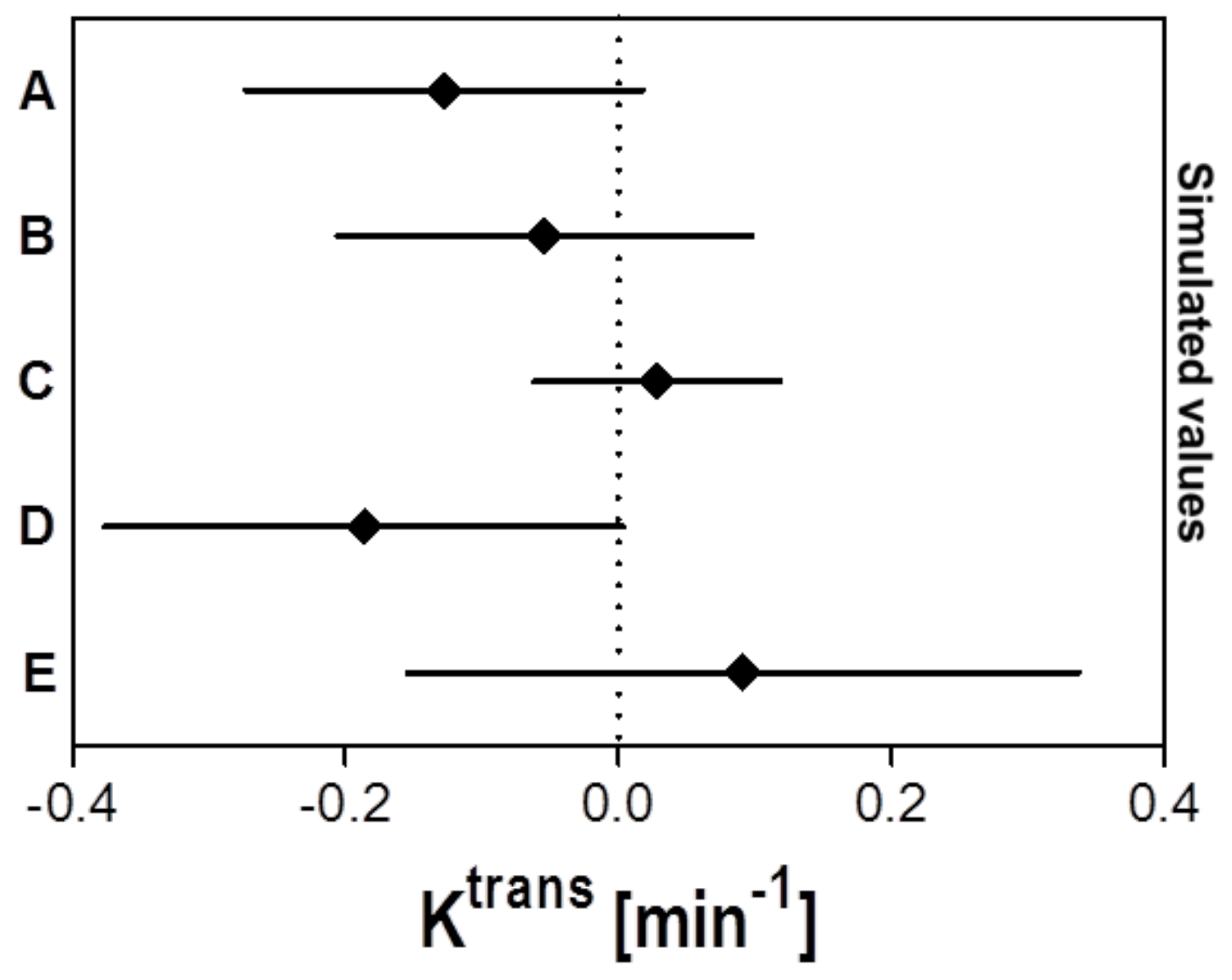

Figure 3 - a 


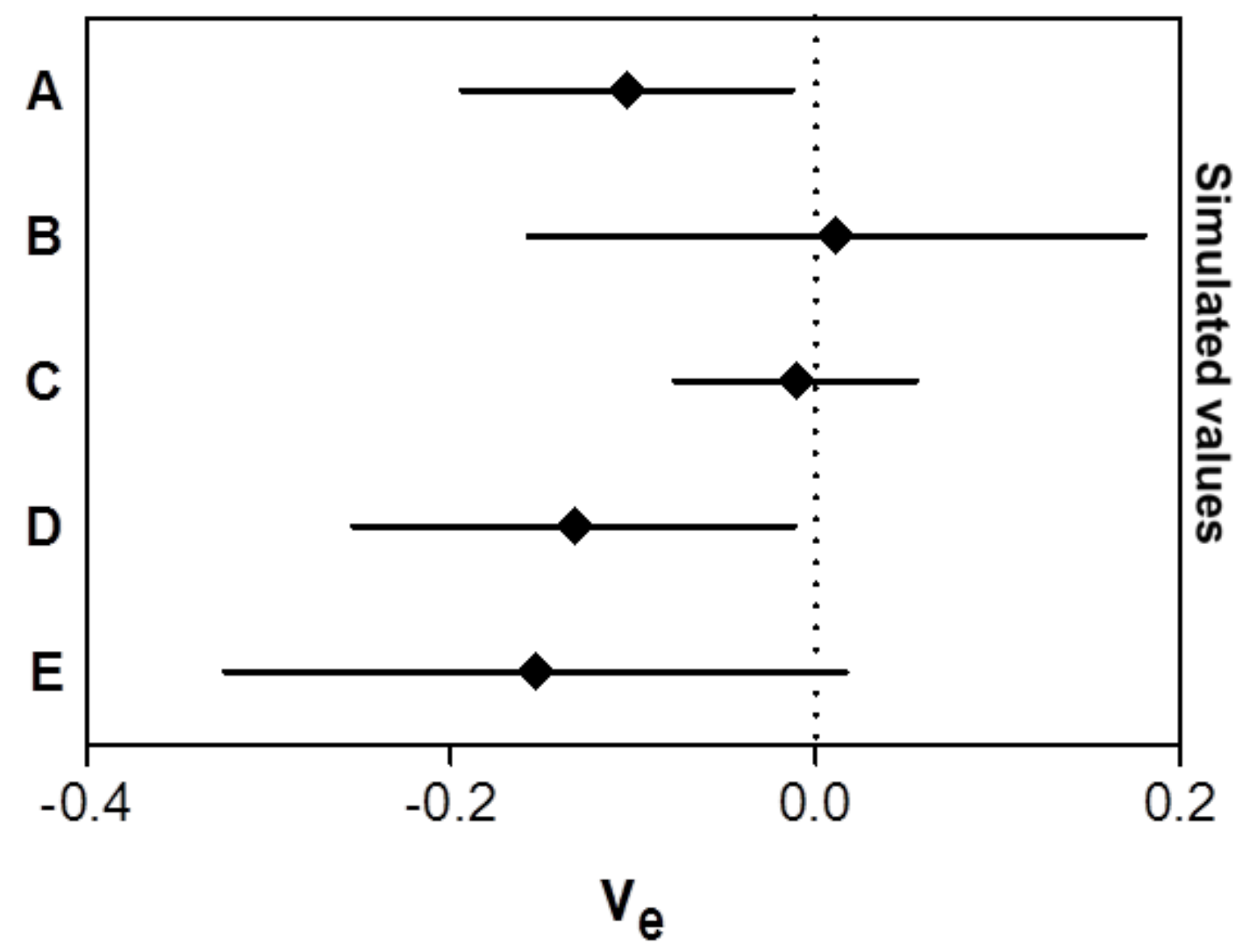

Figure 3 - b 


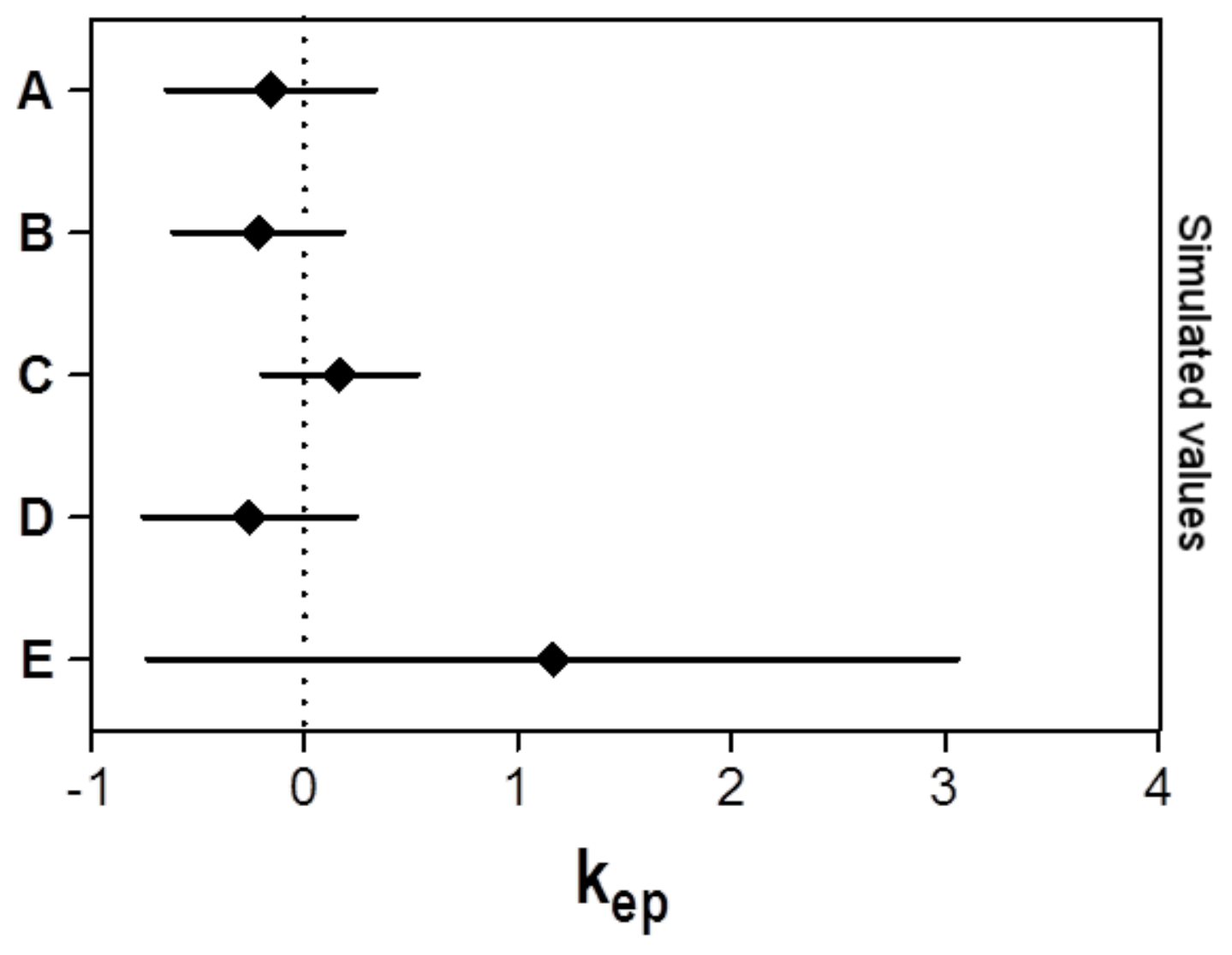

Figure 3 - c 


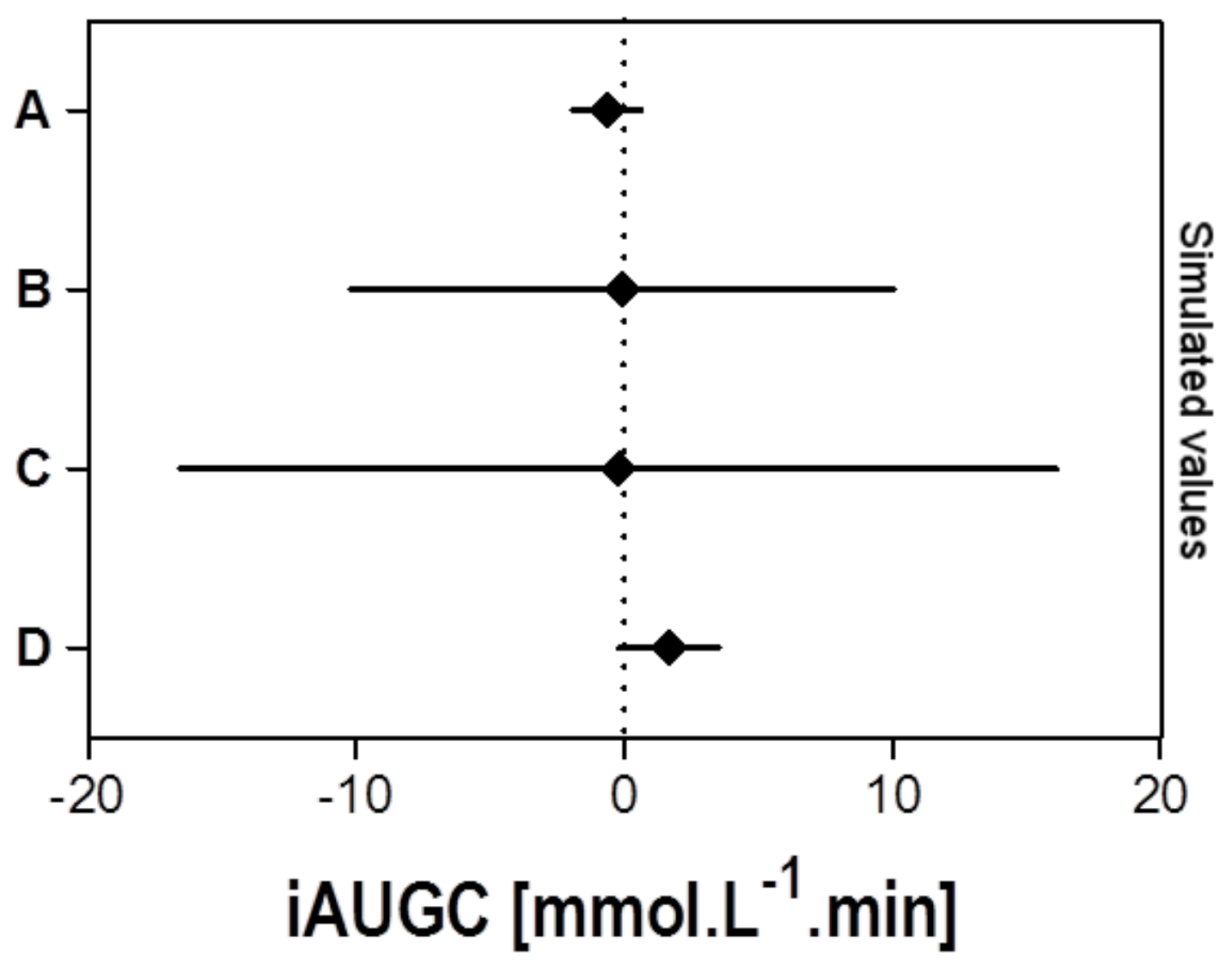

Figure 3 - d 


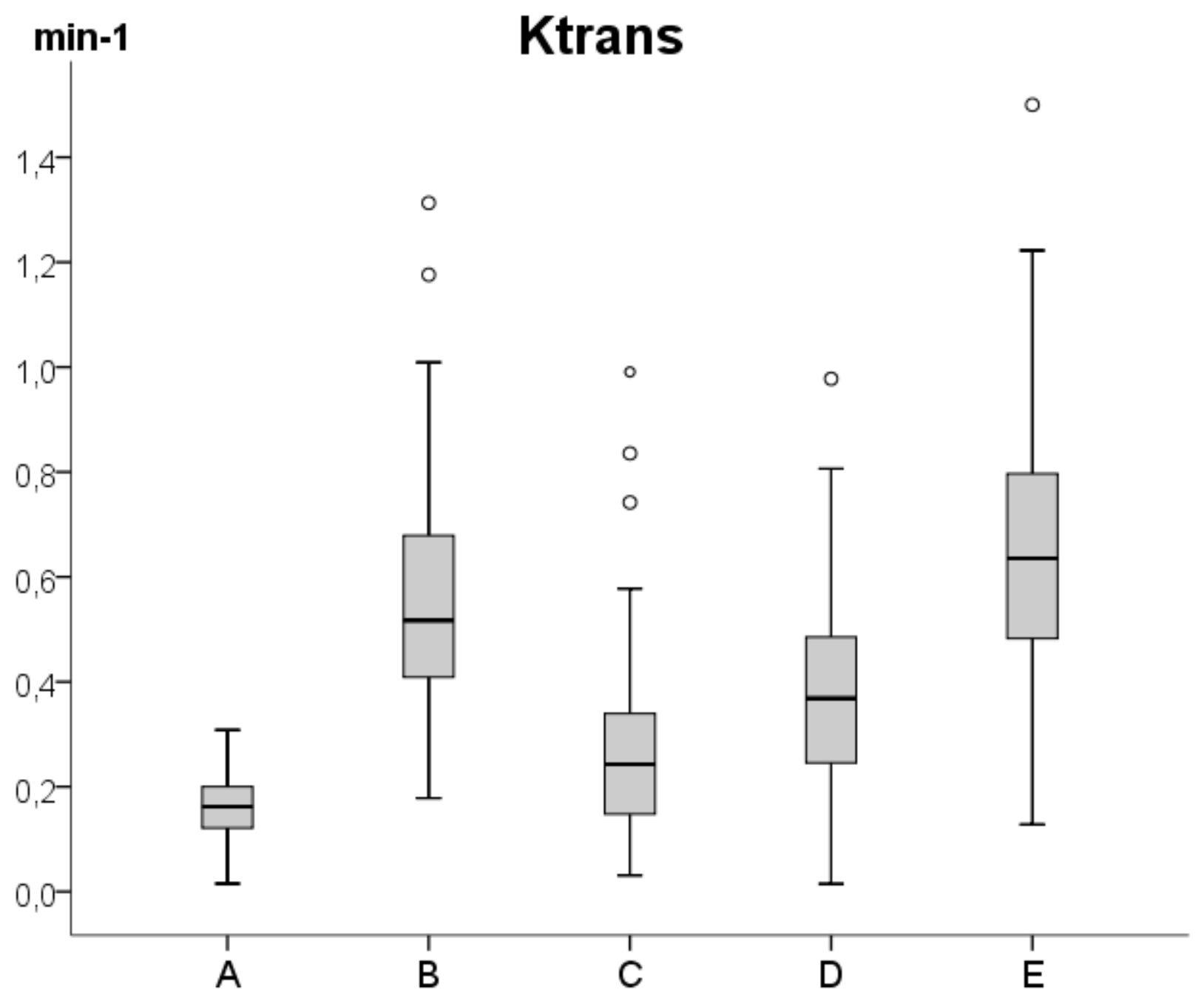

Figure 4 - a 


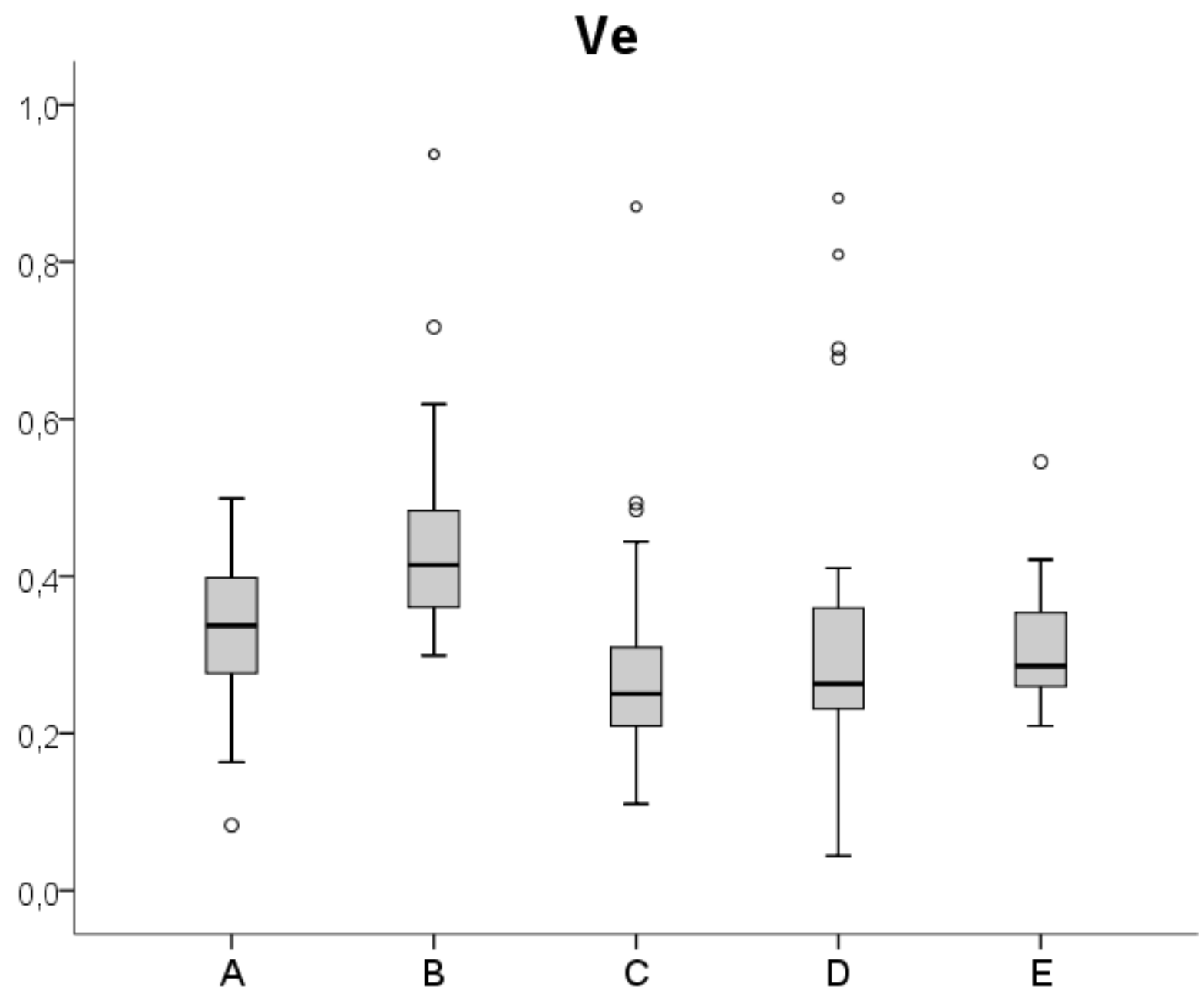

Figure 4 - b 
Kep

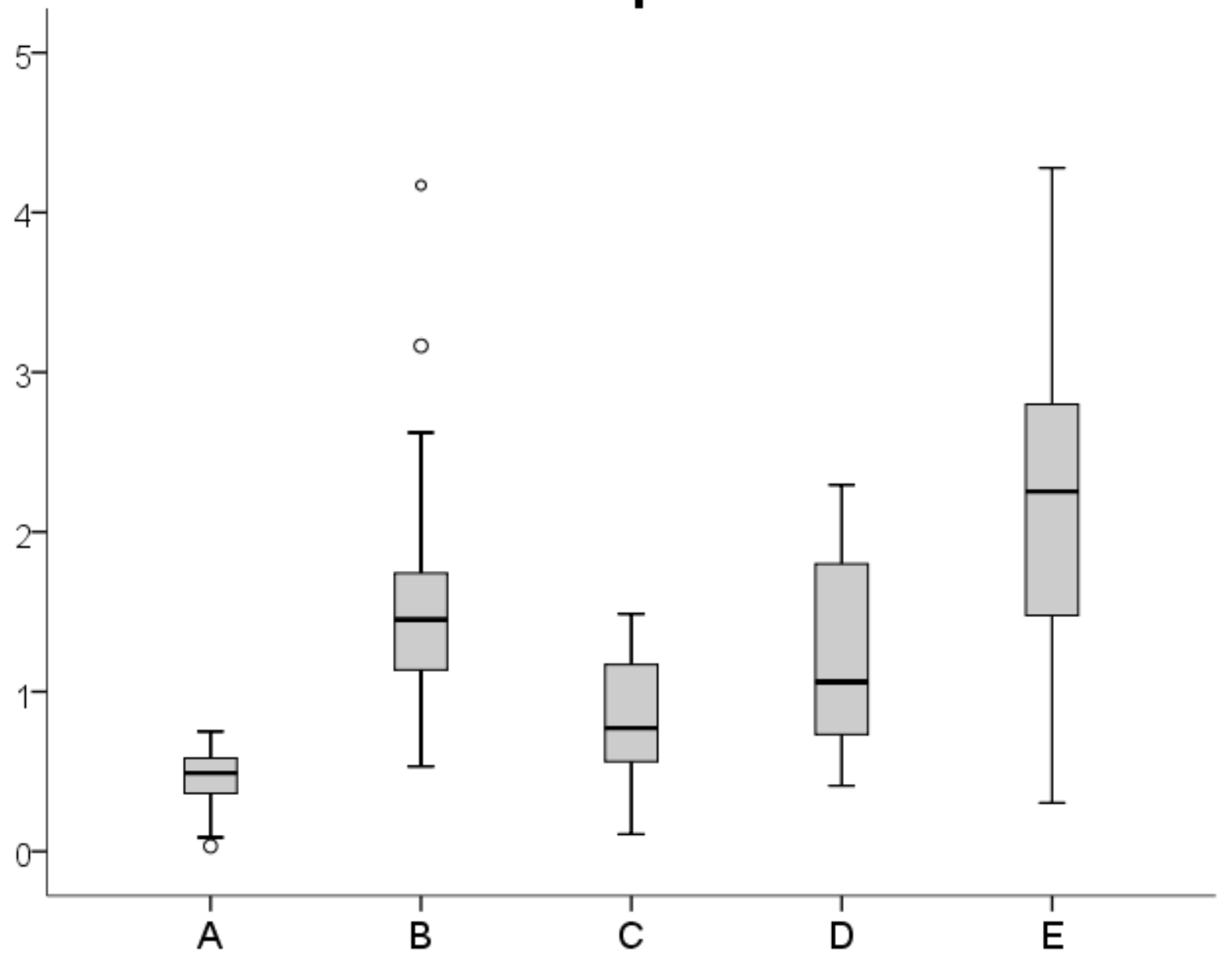

Figure 4-c 


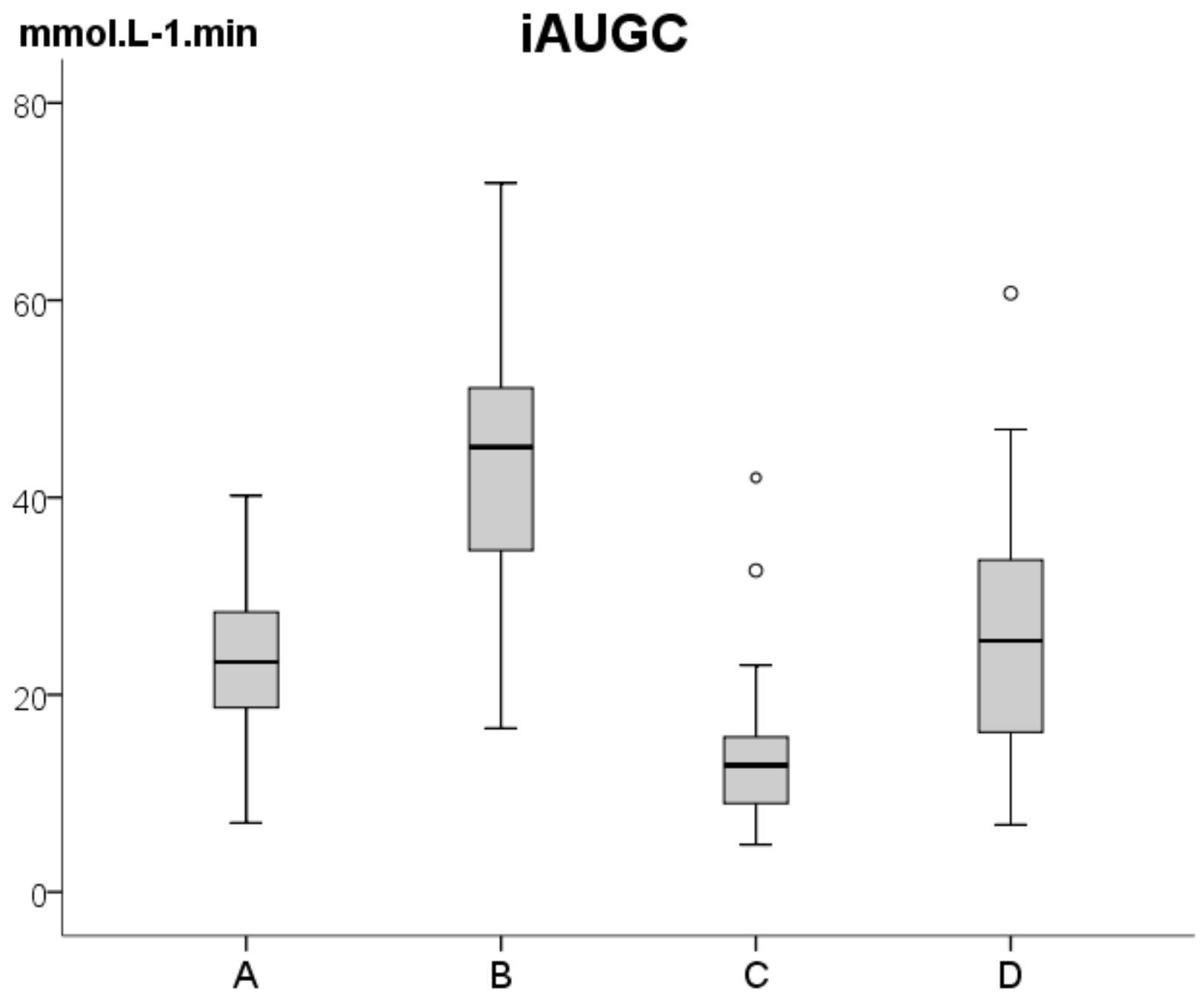

Figure 4-d 


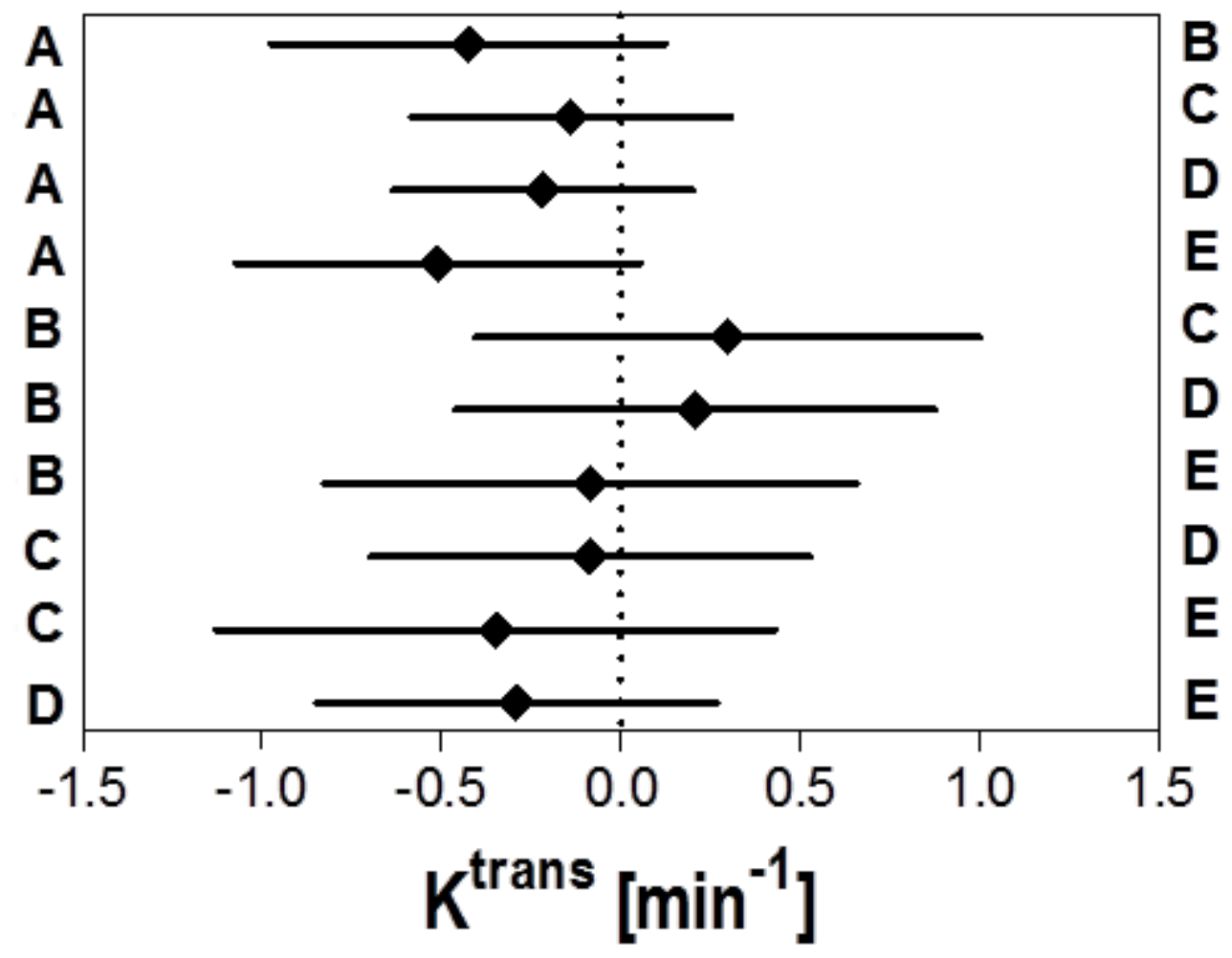

Figure 5 - a 


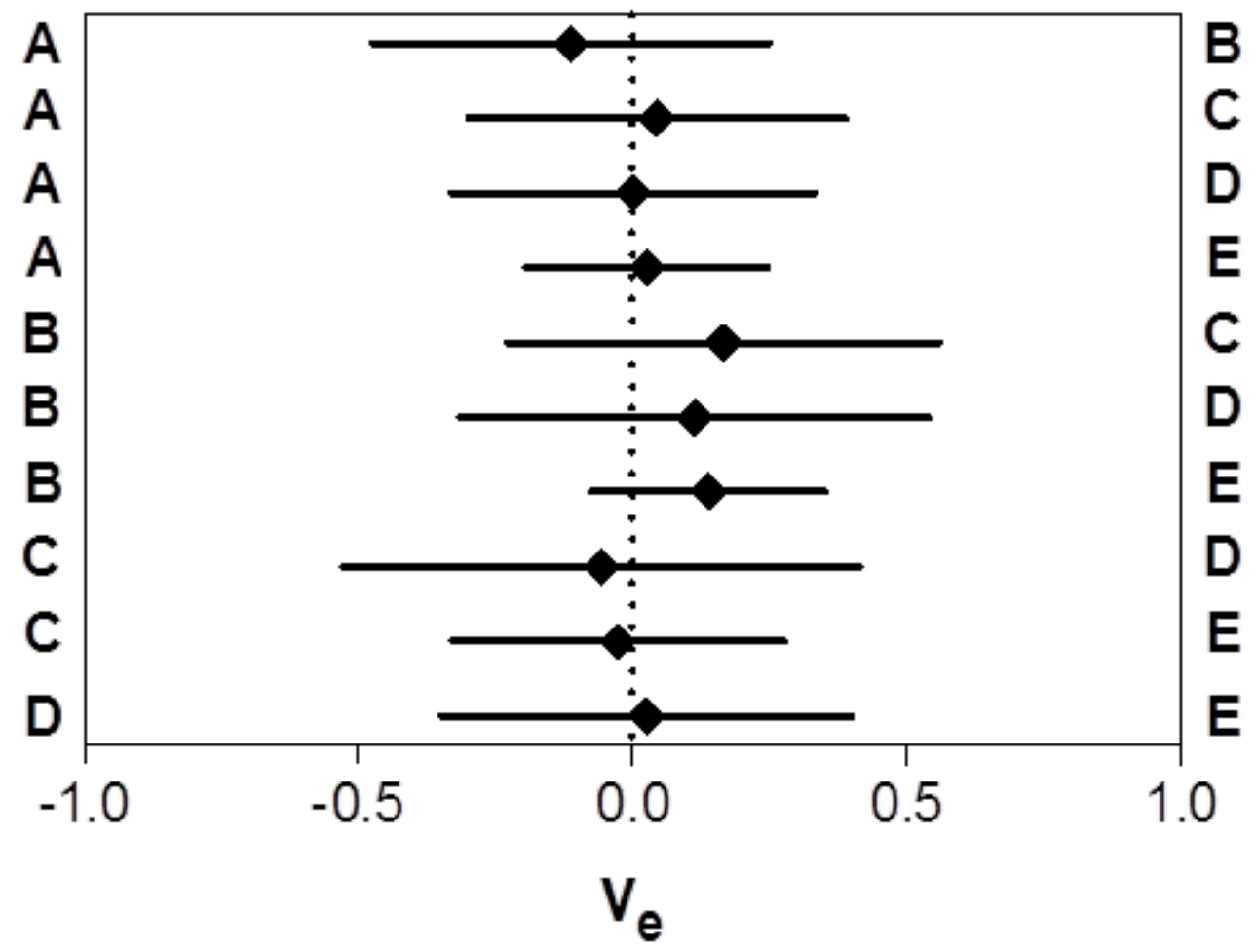

Figure 5 - b 


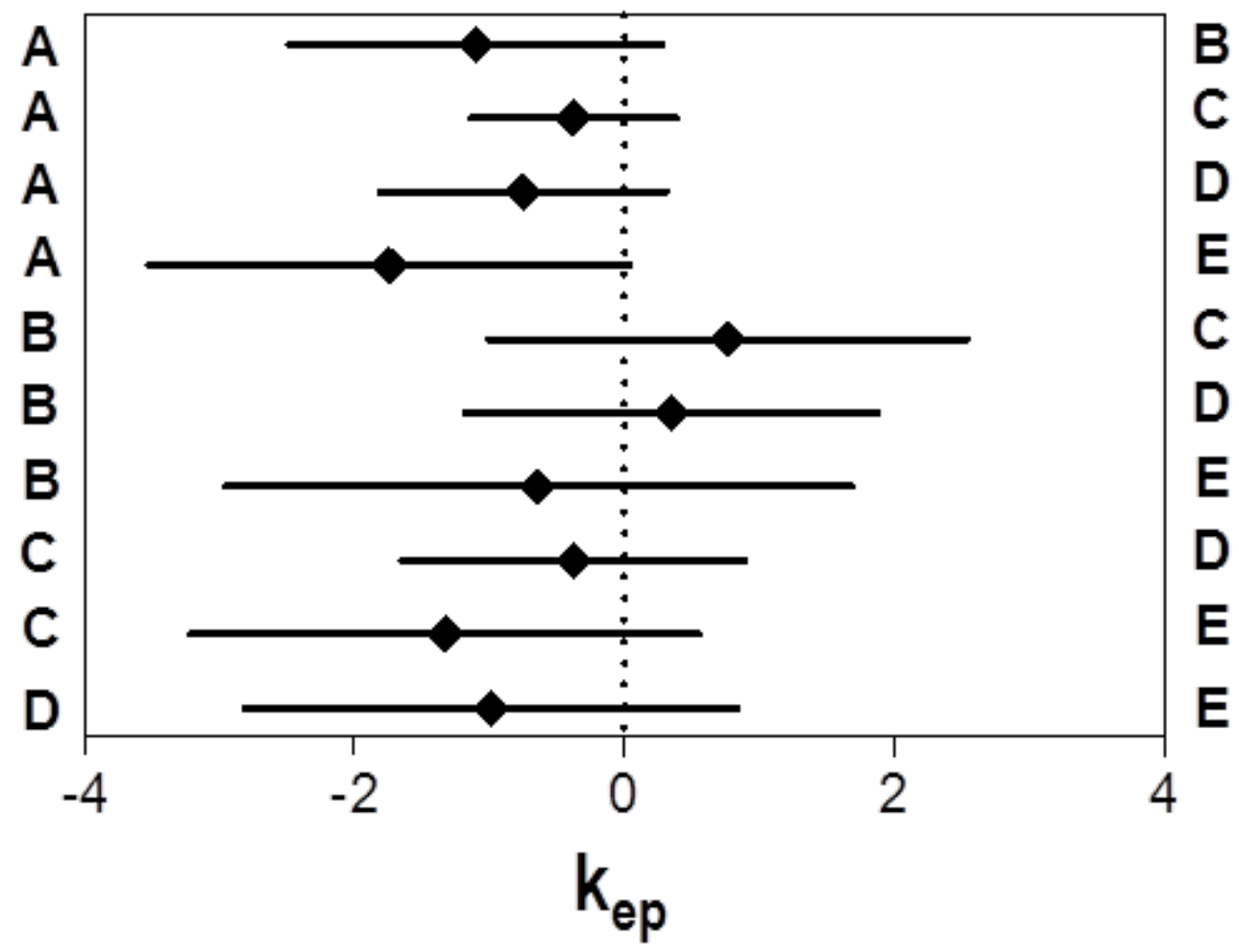

Figure 5-c 


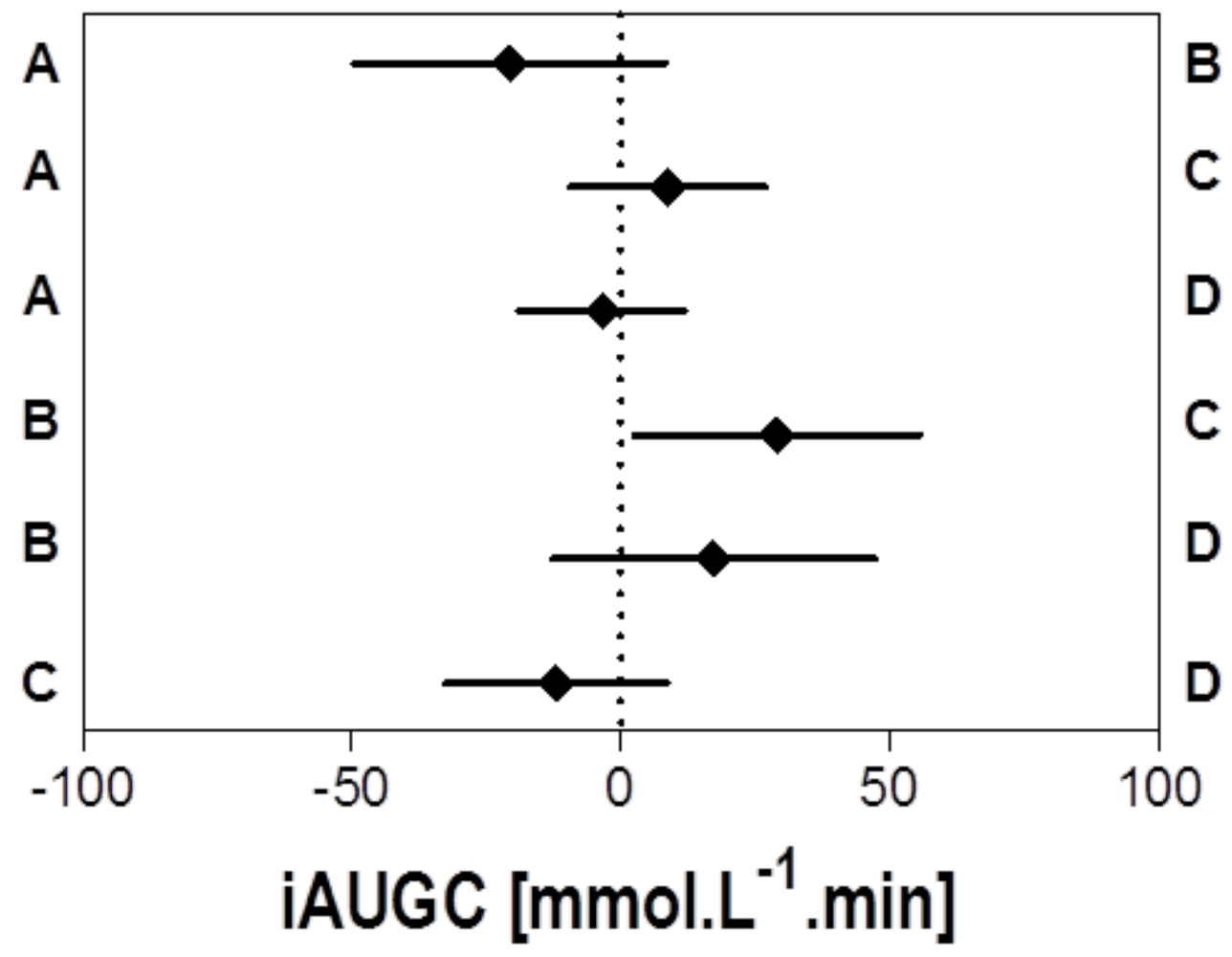

Figure 5-d 